\title{
Dissecting the Mechanism of $(R)$-3-Hydroxybutyrate Dehydrogenase by Kinetic Isotope Effects, Protein Crystallography, and Computational Chemistry
}

Teresa F. G. Machado, Miha Purg, Stephen A. McMahon, Benjamin J. Read, Verena Oehler, Johan Åqvist,* Tracey M. Gloster,* and Rafael G. da Silva*

Cite This: ACS Catal. 2020, 10, 15019-15032

Read Online

ABSTRACT: The enzyme (R)-3-hydroxybutyrate dehydrogenase (HBDH) catalyzes the enantioselective reduction of 3-oxocarboxylates to $(R)-3$ hydroxycarboxylates, the monomeric precursors of biodegradable polyesters. Despite its application in asymmetric reduction, which prompted several engineering attempts of this enzyme, the order of chemical events in the active site, their contributions to limit the reaction rate, and interactions between the enzyme and non-native 3-oxocarboxylates have not been explored. Here, a combination of kinetic isotope effects, protein crystallography, and quantum mechanics/molecular mechanics (QM/MM) calculations were employed to dissect the $\mathrm{HBDH}$ mechanism. Initial velocity patterns and primary deuterium kinetic isotope effects establish a steady-state ordered kinetic mechanism for acetoacetate reduction by a psychrophilic and a mesophilic $\mathrm{HBDH}$, where hydride transfer is not rate limiting. Primary

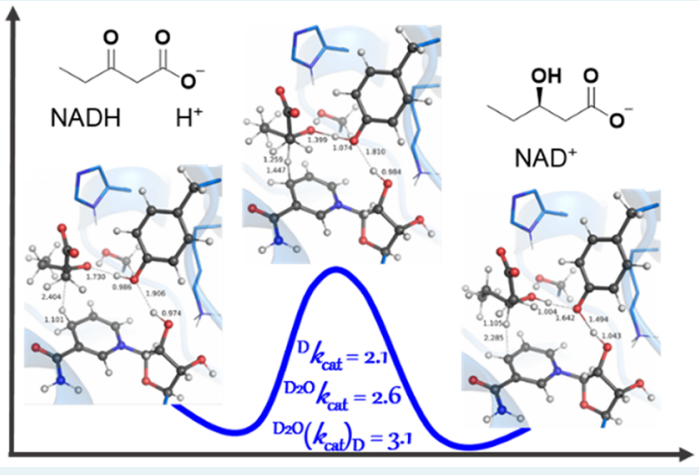
deuterium kinetic isotope effects on the reduction of 3-oxovalerate indicate that hydride transfer becomes more rate limiting with this non-native substrate. Solvent and multiple deuterium kinetic isotope effects suggest hydride and proton transfers occur in the same transition state. Crystal structures were solved for both enzymes complexed to $\mathrm{NAD}^{+}$:acetoacetate and $\mathrm{NAD}^{+}: 3$-oxovalerate, illustrating the structural basis for the stereochemistry of the 3-hydroxycarboxylate products. QM/MM calculations using the crystal structures as a starting point predicted a higher activation energy for 3-oxovalerate reduction catalyzed by the mesophilic HBDH, in agreement with the higher reaction rate observed experimentally for the psychrophilic orthologue. Both transition states show concerted, albeit not synchronous, proton and hydride transfers to 3-oxovalerate. Setting the MM partial charges to zero results in identical reaction activation energies with both orthologues, suggesting the difference in activation energy between the reactions catalyzed by cold- and warm-adapted HBDHs arises from differential electrostatic stabilization of the transition state. Mutagenesis and phylogenetic analysis reveal the catalytic importance of His150 and Asn 145 in the respective orthologues.

KEYWORDS: 3-hydroxybutyrate dehydrogenase, isotope effects, hydride transfer, quantum mechanics/molecular mechanics, enzyme catalysis

\section{INTRODUCTION}

(R)-3-Hydroxyburyrate dehydrogenase (HBDH) (EC 1.1.1.30) catalyzes the NADH-dependent asymmetric reduction of acetoacetate to $(R)$-3-hydroxyburyrate with 3oxovalerate as an alternative substrate turned over more slowly by the enzyme (Scheme 1). ${ }^{1}$ HBDH belongs to the short-chain dehydrogenase/reductase (SDR) superfamily, one of the largest known protein groups present in all three domains of

Scheme 1. HBDH-Catalyzed Reaction

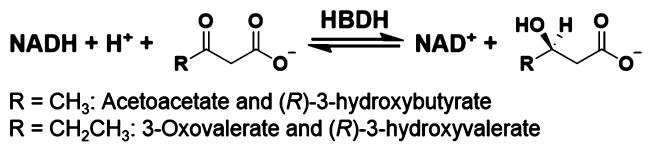

life. ${ }^{2}$ SDRs are characterized by relatively low amino acid sequence identity but highly conserved three-dimensional architecture and a Ser-Tyr-Lys catalytic triad. ${ }^{3}$

Native and engineered ketoreductases from the SDR superfamily are widely used in biocatalysis for the enantioselective synthesis of chiral alcohols to serve as building blocks in the synthesis of pharmaceuticals and fine chemicals. ${ }^{4,5} \mathrm{HBDH}$ is particularly interesting as it generates $(R)$-3-hydroxycarbox-

Received: October 30, 2020

Revised: November 24, 2020

Published: December 7, 2020

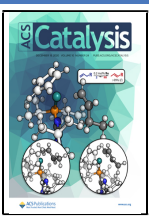


ylates, which are broadly used chiral precursors that can be further modified to introduce a second stereocenter. ${ }^{6}$ For instance, the native product of the HBDH reaction, (R)-3hydroxybutyrate, is a precursor in the synthesis of carbapenem antibiotics, ${ }^{7}$ and $(R)$-3-hydroxybutyrate, $(R)$-3-hydroxyvalerate, and ( $R$ )-3-hydroxyhexanoate, all products of $\mathrm{HBDH}$ catalyzed reduction of 3-oxocarboxylates, ${ }^{1}$ are the monomeric components of biodegradable polyesters. ${ }^{8}$ Accordingly, recent publications highlight several ongoing $\mathrm{HBDH}$ engineering efforts to improve production of its native and non-native products via biocatalysis and synthetic biology. ${ }^{9-11}$

While crystal structures ${ }^{12-16}$ and functional studies ${ }^{17,18}$ have shed light on the basics of $\mathrm{HBDH}$-catalyzed reaction, the nature of rate-limiting chemical steps, the relative timing of hydride and proton transfers, and the interactions between $\mathrm{HBDH}$ and non-native substrates remain elusive. Dissecting the mechanistic underpinnings of enzymatic reactions, especially rate-limiting steps with native and non-native substrates and protein architecture-imposed restrictions on substrate specificity, has the potential to enable rational enzyme engineering. ${ }^{19}$

We recently determined the temperature-rate profiles of a psychrophilic and a mesophilic HBDH from Psychrobacter arcticus and Acinetobacter baumannii, respectively, and uncovered a temperature-dependent change in the ratelimiting step for both orthologues. ${ }^{20}$ Here, using $\mathrm{HBDH}$ from $P$. arcticus $(\mathrm{PaHBDH})$ and $A$. baumannii $(\mathrm{AbHBDH})$, we employ steady-state kinetics, $\mathrm{pH}$-rate profiles, primary, solvent, and multiple deuterium kinetic isotope effects, X-ray crystallography, and quantum mechanics/molecular mechanics (QM/MM) calculations to put forth the most detailed description to date of the chemical mechanism of the reaction catalyzed by this enzyme.

\section{MATERIALS AND METHODS}

Materials. All commercially available chemicals were used without further purification. Reduced nicotinamide adenine dinucleotide $(\mathrm{NADH})$, oxidized nicotinamide adenine dinucleotide $\left(\mathrm{NAD}^{+}\right)$, D-glucose, Pseudomonas sp. glucose dehydrogenase, deuterium oxide $\left(\mathrm{D}_{2} \mathrm{O}\right)$ (99.9 atom \% D), and acetoacetate were purchased from Sigma-Aldrich. Deuteriumlabeled D-glucose (1-D, 98\%) was purchased from Cambridge Isotope Laboratories, and 3-oxovalerate was purchase from Carbosynth. $\mathrm{PaHBDH}$ and $\mathrm{AbHBDH}$ were expressed and purified as previously described. ${ }^{20}$

Synthesis and Purification of NADH and $4 S$ [4- $\left.{ }^{2} \mathrm{H}\right] \mathrm{NADH}$. NADH and $4 S-\left[4{ }^{2} \mathrm{H}\right] \mathrm{NADH}$ (NADD) were synthesized and purified as previously described. ${ }^{21,22}$ Briefly, a solution $(12 \mathrm{~mL})$ containing $0.05 \mathrm{M}$ sodium bicarbonate, 0.03 $\mathrm{M}$ D-glucose or $\left[1-^{2} \mathrm{H}\right] \mathrm{D}$-glucose, $0.015 \mathrm{M} \mathrm{NAD}^{+}$, and $1 \mathrm{mg}$ of glucose dehydrogenase at $\mathrm{pH} 7.5$ was allowed to react at room temperature. After $5 \mathrm{~h}$ the solution $\mathrm{pH}$ was readjusted to 7.5 and purified on a BioRad NGC Liquid Chromatography System using a $20 \mathrm{~mL}$ HiTrap Q HP column equilibrated with water and eluted with a linear gradient of 20 column volumes of $1 \mathrm{M}$ sodium bicarbonate. Fractions with a $260 \mathrm{~nm} / 340 \mathrm{~nm}$ absorbance ratio $\leq 2.3$ were pooled, fast frozen, and freeze dried. Prior to each experiment using $\mathrm{NADH}$ and NADD solutions, their concentrations were determined spectrophotometrically at $340 \mathrm{~nm}$ based on $\varepsilon=6220 \mathrm{M}^{-1} \mathrm{~cm}^{-1}$.

$\mathrm{PaHBDH}$ and $\mathrm{AbHBDH}$ Activity Assay. All assays were performed under initial rate conditions as previously described, $^{20}$ and reactions were started by addition of
$\mathrm{NADH}$ after 3 min incubation at $10{ }^{\circ} \mathrm{C}$ and $\mathrm{pH} 7.0$ unless stated otherwise. Reaction rates were measured in a Shimadzu UV-2600 spectrophotometer by monitoring the decrease in absorbance at $340 \mathrm{~nm}\left(\varepsilon=6220 \mathrm{M}^{-1} \mathrm{~cm}^{-1}\right)$ due to oxidation of $\mathrm{NADH}$ in $1 \mathrm{~cm}$ optical path length quartz cuvettes (Hellma).

$\mathrm{PaHBDH}$ and $\mathrm{AbHBDH}$ Initial Velocity Patterns. Initial rates were measured at $10{ }^{\circ} \mathrm{C}$ in the presence of varying concentrations of $\mathrm{NADH}(0.005-0.08 \mathrm{mM}$ for $\mathrm{PaHBDH}$; $0.04-0.64 \mathrm{mM}$ for $A b \mathrm{HBDH})$ and acetoacetate (0.025-0.4 $\mathrm{mM}$ for $\mathrm{PaHBDH}$; $0.05-0.8 \mathrm{mM}$ for $A b \mathrm{HBDH}$ ) with either 5 $\mathrm{nM} P a \mathrm{HBDH}$ or $50 \mathrm{nM} A b \mathrm{HBDH}$. For $A b \mathrm{HBDH}$, the lowest concentration points for both acetoacetate $(0.05 \mathrm{mM})$ and $\mathrm{NADH}(0.04 \mathrm{mM})$ were not included in the fit. All measurements were performed at least in duplicate.

PaHBDH-NADH Equilibrium Dissociation Constant $\left(K_{\mathrm{D}}\right)$. Measurements were carried out at $25{ }^{\circ} \mathrm{C}$ in a Spectramax M3 multimode microplate reader (Molecular Devices) $\left(\lambda_{\mathrm{ex}}=\right.$ $\left.340 \mathrm{~nm}, \lambda_{\mathrm{em}} 420 \mathrm{~nm}\right)$. Fluorescence assays $(110 \mu \mathrm{L})$ for $3 \mu \mathrm{M}$ $\mathrm{NADH}$ were measured in $100 \mathrm{mM}$ HEPES, pH 7.0 in the presence of increasing concentrations of $\mathrm{PaHBDH}(0,2,4,8$, 16, and $32 \mu \mathrm{M})$. All measurements were carried out in triplicate.

$A b \mathrm{HBDH}-\mathrm{NADH} K_{\mathrm{D}}$. Isothermal titration calorimetry (ITC) measurements were carried out at $25{ }^{\circ} \mathrm{C}$ in a MicroCal PEAQ-ITC calorimeter (Malvern Instruments). Protein and NADH were solubilized in the same buffer $(100 \mathrm{mM}$ HEPES, $\mathrm{pH}$ 7.0). After an injection of $0.4 \mu \mathrm{L}, 19$ successive injections of $2 \mu \mathrm{L}$ of $0.8 \mathrm{mM} \mathrm{NADH}$ were carried out into $300 \mu \mathrm{L}$ of 30 $\mu \mathrm{M} A b \mathrm{HBDH}$ with $120 \mathrm{~s}$ intervals between successive injections and a reference power of $10 \mu \mathrm{cal} \mathrm{s}{ }^{-1}$. Heats of dilution for each experiment were measured by titrating ligand into assay buffer and subtracted from the corresponding binding curve. All measurements were performed in duplicate. Data were fitted to a single-site model as implemented in the PEAQ-ITC analysis software (Malvern Instruments).

pH-Rate Profiles. The $\mathrm{pH}$ dependence of the kinetic parameters was determined by measuring the initial velocities at $10{ }^{\circ} \mathrm{C}$ in the presence of varying concentrations of one substrate (For $\mathrm{PaHBDH}$ : $0.0125-0.2 \mathrm{mM}$ 3-oxovalerate and $6.25 \times 10^{-4}-0.01 \mathrm{mM}$ NADH, $\mathrm{pH} 6.5-8.0 ; 0.025-0.4 \mathrm{mM} 3-$ oxovalerate and $6.25 \times 10^{-4}-0.01 \mathrm{mM}$ NADH, pH 8.5; 0.05$0.8 \mathrm{mM}$ 3-oxovalerate and 0.00125-0.02 mM NADH, pH 9.0. For $A b \mathrm{HBDH}: 0.025-0.4 \mathrm{mM}$ 3-oxovalerate and $0.01-0.16$ $\mathrm{mM} \mathrm{NADH}, \mathrm{pH}$ 6.5-8.5; 0.05-0.8 mM 3-oxovalerate and 0.01-0.16 mM NADH, $\mathrm{pH}$ 9.0.) and a fixed, saturating concentration of the other (the upper value in the corresponding range when that substrate had its concentration fixed), employing a composite buffer system of $100 \mathrm{mM}$ HEPES and 100 mM CHES. A pH range of 6.5-9.0 was used. The concentration of $\mathrm{PaHBDH}$ was $10 \mathrm{nM}$ and that of AbHBDH $576 \mathrm{nM}$. To ensure enzyme stability at the extremes of the $\mathrm{pH}$ range, enzymes were diluted in buffer at either $\mathrm{pH}$ 6.5 or 9.5 prior to activity assay at $\mathrm{pH}$ 7.0. All measurements were performed at least in duplicate.

$\mathrm{PaHBDH}$ and $A b \mathrm{HBDH}$ Saturation Kinetics in the Presence of Glycerol. $\mathrm{PaHBDH}(10 \mathrm{nM})$ and $A b \mathrm{HBDH}$ $(576 \mathrm{nM})$ initial rates with 3-oxovalerate were measured at 10 ${ }^{\circ} \mathrm{C}$ at saturating concentrations of one substrate and varying concentrations of the other, either 3-oxovalerate (for PaHBDH, 0.0125-0.2 mM; for AbHBDH, 0.025-0.4 mM) or $\mathrm{NADH}$ (for $\mathrm{PaHBDH}, 6.25 \times 10^{-4}-0.01 \mathrm{mM}$; for $A b \mathrm{HBDH}, 0.01-0.16 \mathrm{mM})$ in the presence of $0 \%$ and $7 \%$ 
glycerol $(v / v)$. The concentration of glycerol was determined to mimic the increase in viscosity caused by $\mathrm{D}_{2} \mathrm{O}$ at $10{ }^{\circ} \mathrm{C}$. All measurements were performed in duplicate.

$\mathrm{PaHBDH}$ and $\mathrm{AbHBDH}$ Steady-State Kinetic Isotope Effects. Primary deuterium kinetic isotope effects were measured using $\mathrm{NADH}$ or NADD with either acetoacetate or 3-oxovalerate as substrate in $100 \mathrm{mM}$ HEPES, $\mathrm{pH} 7.0$ at 10 ${ }^{\circ} \mathrm{C}$. Isotope effects were determined by measuring the initial rates in the presence of varying concentrations of one substrate (For $\mathrm{PaHBDH}$ : $0.025-0.4 \mathrm{mM}$ acetoacetate and $0.005-0.08$ $\mathrm{mM} \mathrm{NADH}$ or $0.0025-0.04 \mathrm{mM}$ NADD; $0.05-0.2 \mathrm{mM} 3$ oxovalerate and $0.0025-0.01 \mathrm{mM} \mathrm{NADH}$ or NADD. For $A b \mathrm{HBDH}: \quad 0.05-0.8 \mathrm{mM}$ acetoacetate and $0.02-0.32 \mathrm{mM}$ $\mathrm{NADH}$ or NADD; $0.025-0.4 \mathrm{mM} 3$-oxovalerate and $0.01-$ $0.16 \mathrm{mM} \mathrm{NADH}$ or NADD.) and a fixed, saturating concentration of the other (the upper value in the corresponding range when that substrate had its concentration fixed). Kinetic isotope effects were calculated by dividing a given kinetic constant $\left(k_{\mathrm{cat}}\right.$ or $\left.k_{\mathrm{cat}} / K_{\mathrm{M}}\right)$ obtained with $\mathrm{NADH}$ by the corresponding kinetic constant obtained with NADD. Measurements were performed in triplicate.

Solvent deuterium kinetic isotope effects were determined at $10{ }^{\circ} \mathrm{C}$ and $\mathrm{pL}=7.0(\mathrm{pD}=\mathrm{pH}+0.4)^{23}$ using 3-oxovalerate and $\mathrm{NADH}$ as substrates by measuring the initial velocities at varying concentrations of one substrate in $\mathrm{H}_{2} \mathrm{O}$ or $91 \% \mathrm{D}_{2} \mathrm{O}$ (For PaHBDH: $0.05-0.2 \mathrm{mM}$ 3-oxovalerate, 0.0025-0.01 mM NADH. For AbHBDH: 0.1-0.4 mM 3-oxovalerate, 0.4$0.16 \mathrm{mM} \mathrm{NADH}$.) and a fixed, saturating concentration of the other (the upper value in the corresponding range when that substrate had its concentration fixed). Multiple deuterium kinetic isotope effects were determined by measuring the solvent deuterium kinetic isotope effect with 3-oxovalerate and NADD as substrates at varying concentrations of one substrate (For PaHBDH: $0.05-0.2 \mathrm{mM}$ 3-oxovalerate, 0.0025-0.01 mM NADD. For AbHBDH: 0.1-0.4 mM 3-oxovalerate, 0.4$0.16 \mathrm{mM}$ NADD.) and a fixed, saturating concentration of the other (the upper value in the corresponding range when that substrate had its concentration fixed). All measurements were performed in triplicate. Solvent and multiple kinetic isotope effects were calculated the same way as the primary kinetic isotope effects at $10{ }^{\circ} \mathrm{C}$ except for a correction to account for the $91 \%$ labeling.

Oligomeric State Determination. The oligomeric states of $\mathrm{PaHBDH}$ and $\mathrm{AbHBDH}$ in solution were determined by analytical gel filtration with a Superdex 200 10/300 GL column (GE Healthcare) at room temperature. Samples were loaded onto the column at $1 \mathrm{mg} / \mathrm{mL}$ and run in $20 \mathrm{mM}$ HEPES, $\mathrm{pH}$ 8.0. Vitamin B12 (1350 Da), horse myoglobin (17000 Da), chicken ovalbumin (44000 Da), bovine $\gamma$-globulin (158000 $\mathrm{Da})$, and bovine thyroglobulin (670000 Da) (Bio-Rad) were used as MW standards. The logarithm of the MW of the standards was plotted against the ratio of the elution volume $\left(v_{\mathrm{e}}\right)$ to the void volume $\left(v_{\mathrm{o}}\right)$. The points were then fitted to a linear regression, and the values of the slope and intercept were used to determine the molecular mass of $\mathrm{PaHBDH}$ and $\mathrm{Ab \textrm {HBDH }}$.

Crystallization of $\mathrm{PaHBDH}$ and $\mathrm{AbHBDH}$. An initial crystallization screen was performed with JCSG-plus HT-96 (Molecular Dimensions). Sitting drops (150 $\mathrm{nL}$ of protein and $150 \mathrm{~nL}$ of crystallization solution, $300 \mathrm{~nL}$ of protein and 150 $\mathrm{nL}$ of crystallization solution, and $150 \mathrm{~nL}$ of protein and 300 $\mathrm{nL}$ of crystallization solution) were set up using an Art Robbins Gryphon crystallization robot with 96-well INTELLI-PLATEs
(1 $\mu \mathrm{L}$ well volume, Art Robbins). Plates were incubated at room temperature, and drops were visualized using an optical microscope. $\mathrm{PaHBDH}$ was crystallized at a concentration of 8 $\mathrm{mg} \mathrm{mL} \mathrm{m}^{-1}$, while $A b \mathrm{HBDH}$ was crystallized at a concentration of $4 \mathrm{mg} \mathrm{mL}^{-1}$, and both enzymes were mixed with $5 \mathrm{mM}$ acetoacetate or 3-oxovalerate and $5 \mathrm{mM} \mathrm{NAD}^{+}$before crystallization. $\mathrm{PaHBDH}: \mathrm{NAD}^{+}$:acetoacetate crystallized in 40-50\% (v/v) MPD, 0.2 M calcium chloride, 0.1 M BisTris $\mathrm{pH}$ 5.5-6.0. AbHBDH: $\mathrm{NAD}^{+}$:acetoacetate crystallized in 1923\% (w/v) PEG 3000, 0.1 citrate $\mathrm{pH}$ 4.8-5.0. PaHBDH:$\mathrm{NAD}^{+}: 3$-oxovalerate crystallized in $0.18 \mathrm{M}$ succinic acid, $17.2 \%$ $(\mathrm{w} / \mathrm{v})$ PEG $3350 \mathrm{pH}$ 7.0. AbHBDH:NAD ${ }^{+}: 3$-oxovalerate crystallized in $24.2 \%(\mathrm{w} / \mathrm{v})$ PEG 4000, $0.2 \mathrm{M}$ lithium sulfate, $0.1 \mathrm{M}$ phosphate/citrate $\mathrm{pH}$ 4.2. Crystals grew in 3 days at room temperature.

X-ray Data Collection and Processing. Crystals were cryoprotected with $20 \%$ glycerol in mother liquor and flash cooled in liquid nitrogen. Data sets were collected at the Diamond Light Source, Oxfordshire, UK. PaHBDH:NA$\mathrm{D}^{+}$:acetoacetate and $\mathrm{PaHBDH}: \mathrm{NAD}^{+}: 3$-oxovalerate data were processed through the automated processing pipeline at Diamond with data integration using Fast $\mathrm{DP}^{24}$ (utilizing $\mathrm{XDS}^{25}$ ) and scaled with XSCALE. ${ }^{25}$ AbHBDH:NA$\mathrm{D}^{+}$:acetoacetate data were processed through the $\mathrm{Xia} 2^{26}$ pipeline following data integration in DIALS $^{27}$ and scaling in Aimless. ${ }^{28}$ AbHBDH:NAD ${ }^{+}$:3-oxovalerate data were processed through the automated processing pipeline at Diamond with $\mathrm{Xia2}^{26}$ using XDS for data integration and XSCALE for scaling. ${ }^{25}$ The $\mathrm{NAD}^{+}$-acetoacetate-bound structures of $\mathrm{PaHBDH}$ and $\mathrm{AbHBDH}$ were solved by molecular replacement with PHASER $^{29}$ using the structures of HBDHs from Pseudomonas putida (PDB ID: 2Q2Q chain A) ${ }^{16}$ and Sinorhizobium meliloti (PDB ID: $3 \mathrm{~V} 2 \mathrm{H}$ ) as search models, respectively. Buccaneer ${ }^{30,31}$ and $\mathrm{ARP} / \mathrm{wARP}^{32}$ were used to trace the chain and build the initial models for $P a H B D H$ and $A b \mathrm{HBDH}$, respectively. The $\mathrm{NAD}^{+}: 3$-oxovalerate-bound structures were also solved by molecular replacement with PHASER but using the corresponding $\mathrm{NAD}^{+}$:acetoacetate-bound structures as search models. All models were further refined using cycles of manual model building with $\mathrm{COOT}^{33}$ and automated refinement with Refmac. ${ }^{34}$ The library for 3oxovalerate was created in PRODRG ${ }^{35}$ following a $3 \mathrm{D}$ model generated in Molview. Structures were validated with MolProbity. ${ }^{36}$ All coordinates and structure factor files have been deposited in the Protein Data Bank (PDB accession codes 6ZZS, 6ZZQ, 6ZZP, and 6ZZO).

Site-Directed Mutagenesis. Replacement of $\mathrm{PaHBDH}$ His 150 with alanine or asparagine and of $A b \mathrm{HBDH}$ Asn 145 with alanine or histidine was accomplished by the method of Liu and Naismith ${ }^{37}$ with oligonucleotide primers 5'GTAGCGTCGCT T CACAT GAGGCATCT C T T T T TAAGGCGC-3' and 5'-CATGTGAAGCGACGCTACCCATATAAATTACGGTTCCTCC-3' (H150A-PaHBDH), 5' GTAGCGTCAT T T CACAT GAGGCAT C T C T T T T TAAGGCGC- ${ }^{\prime}$ and $5^{\prime}$-CATGTGAAATGACGCTACCCATATAAATTACGGTTCCTCC-3' (H150N-PaHBDH), 5'CGTCAATTGCAGG C CT TATTGGGTTTGCGGGGAAAGC-3' and 5'-TAAGGCCTGCAATTGACGCCATATTAATAATGCGCCCGT-3' (N145A-AbHBDH), and $5^{\prime}$ CGT CAAT T CAT G G C C T TA T T GGGTTTGCGGGGAAAGC-3' and 5'-TAAGGCCATGAATTGACGCCATATTAATAATGCGCCCGT-3' (N145H-AbHBDH). Successful mutation was confirmed by DNA sequencing (MRC PPU 
DNA Sequencing and Services). All four mutant proteins were produced exactly as reported for the respective wild-type $\mathrm{HBDH}$ (WT-HBDH) ${ }^{20}$ and analyzed for exact mass by electrospray ionization-mass spectrometry (ESI-MS). Initial rates of acetoacetate reduction catalyzed by all $\mathrm{HBDH}$ mutants were measured at $10{ }^{\circ} \mathrm{C}$ under the same conditions as the wildtype enzymes in the presence of varying concentrations of one substrate and a fixed, saturating concentration of the other. For H150A-PaHBDH: $0.035-10.8 \mathrm{mM}$ acetoacetate, $0.16 \mathrm{mM}$ $\mathrm{NADH}, 0.2 \mu \mathrm{M}$ enzyme; $0.002-0.032 \mathrm{mM}$ NADH, $10.8 \mathrm{mM}$ acetoacetate, $0.2 \mu \mathrm{M}$ enzyme. For N145A-AbHBDH: 0.1-5.4 $\mathrm{mM}$ acetoacetate, $0.32 \mathrm{mM} \mathrm{NADH}, 1 \mu \mathrm{M}$ enzyme; 0.005$0.02 \mathrm{mM}$ NADH, $5.4 \mathrm{mM}$ acetoacetate, $0.5 \mu \mathrm{M}$ enzyme. For H150N-PaHBDH: $5.4-21.6 \mathrm{mM}$ acetoacetate, $0.16 \mathrm{mM}$ $\mathrm{NADH}, 7 \mu \mathrm{M}$ enzyme; $0.08-0.16 \mathrm{mM} \mathrm{NADH}, 21.6 \mathrm{mM}$ acetoacetate, $7 \mu \mathrm{M}$ enzyme. For N145H-AbHBDH: 0.7-21.6 $\mathrm{mM}$ acetoacetate, $0.32 \mathrm{mM} \mathrm{NADH}, 0.2 \mu \mathrm{M}$ enzyme; $0.0025-$ $0.08 \mathrm{mM} \mathrm{NADH}, 21.6 \mathrm{mM}$ acetoacetate, $0.2 \mu \mathrm{M}$ enzyme. Measurements were performed in duplicate. Differential scanning fluorimetry (DSF) analysis of the mutant proteins was carried out in triplicate exactly as reported for their WT counterparts. $^{20}$

Multiple Sequence Alignment and Construction of the HBDH Phylogenetic Tree. A multiple-sequence alignment and phylogenetic tree of $\mathrm{HBDH}$ amino acid sequences was built simultaneously using the Bayesian Markov Chain Monte Carlo (MCMC) algorithm implemented in BAliPhy. ${ }^{38,39}$ Analysis was performed using the RS07 insertion/ deletion model and the LG08 amino acid substitution matrix with gamma-distributed rates across sites $(n=4)$. Two independent MCMC analyses were run until the average standard deviation of the split differences and potential scale reduction factor with an $80 \%$ credible interval fell below 0.01 and 1.01 , respectively. The first $25 \%$ of iterations were skipped when producing the multiple sequence alignment and the corresponding maximum a posteriori tree based on the posterior probability. $\mathrm{HBDH}$ sequences were selected from the UniProtKB/Swiss-Prot database using the $\mathrm{PaHBDH}$ sequence as the query. Sequences showing more than $80 \%$ sequence identity to the query sequence were excluded from the search. The selection process aimed to amplify genetic diversity and maximize the number of bacterial phyla while also capturing $\mathrm{HBDHs}$ from mesophilic, psychrophilic, thermophilic, or halophilic organisms. An out group consisting of 3-oxoacyl-(acyl-carrier-protein) reductases (FabG) from Clostridium estertheticum and Chlorobium phaeovibrioides and glucose-1-dehydrogenase (GDH) from Petrotoga mexicana was included to root the tree.

Kinetic and DSF Data Analysis. Kinetic data were analyzed by the nonlinear regression function of SigmaPlot 14 (SPSS Inc.). Data points and error bars in graphs and $K_{\mathrm{D}}$ for $A b \mathrm{HBDH}$ represent mean \pm standard error of independent measurements, while kinetic constants and $K_{\mathrm{D}}$ for $\mathrm{PaHBDH}$ represent mean \pm fitting error unless otherwise stated. Initial velocity patterns were globally fitted to eq 1 , which describes both rapid equilibrium random and steady-state ordered kinetic mechanisms, where $v$ is the initial rate, $E_{\mathrm{T}}$ is total enzyme concentration, $k_{\text {cat }}$ is the steady-state catalytic constant, $A$ and $B$ are the first and second substrates to bind to the enzyme, respectively, $K_{\mathrm{ia}}$ is the apparent dissociation constant for the complex between the enzyme and substrate $A$ when the concentration of $\mathrm{B}$ approaches zero, and $K_{\mathrm{a}}$ and $K_{\mathrm{b}}$ are Michaelis constants for substrates $\mathrm{A}$ and $\mathrm{B}$, respectively.

$$
\frac{v}{E_{\mathrm{T}}}=\frac{k_{\mathrm{cat}} \mathrm{AB}}{K_{\mathrm{ia}} K_{\mathrm{b}}+K_{\mathrm{a}} \mathrm{B}+K_{\mathrm{b}} \mathrm{A}+\mathrm{AB}}
$$

The NADH equilibrium dissociation constant for $\mathrm{PaHBDH}$ was determined through eq 2 , where $F$ is the measured fluorescence, $F_{0}$ is the $\mathrm{NADH}$ fluorescence in the absence of $\mathrm{PaHBDH}, F_{\max }$ is the maximum fluorescence, $[N]$ is the concentration of $\mathrm{NADH},[E]$ is the concentration of $\mathrm{PaHBDH}$, and $K_{\mathrm{D}}$ is the equilibrium dissociation constant.

$$
F=F_{0}+F_{\max } \frac{\left([N]+[E]+K_{\mathrm{D}}\right)-\sqrt{\left([N]+[E]+K_{\mathrm{D}}\right)-4[N][E]}}{2[N]}
$$

Substrate saturation curves were fitted to eq 3 , where $v$ is the initial rate, $E_{\mathrm{T}}$ is total enzyme concentration, $S$ is the concentration of the varying substrate, $k_{\text {cat }}$ is the steady-state catalytic constant, and $K_{\mathrm{M}}$ is the Michaelis constant.

$$
\frac{v}{E_{\mathrm{T}}}=\frac{k_{\mathrm{cat}} S}{K_{\mathrm{M}}+S}
$$

Data from the $\mathrm{pH}$-rate profiles were fitted to eq 4, where $k$ is the kinetic constant, either $k_{\text {cat }}$ or $k_{\text {cat }} / K_{\mathrm{M}}, C$ is the $\mathrm{pH}$ independent value of $k, H$ is the concentration of protons or deuterons, and $K_{\mathrm{a}}$ is the apparent acid dissociation constant.

$$
\log k=\log \left(\frac{C}{1+K_{\mathrm{a}} / H}\right)
$$

DSF thermal denaturation data were fitted to eq $5,{ }^{40}$ where $F_{\mathrm{U}}$ is fraction unfolded, $T$ is the temperature in ${ }^{\circ} \mathrm{C}, T_{\mathrm{m}}$ is the melting temperature, $c$ is the slope of the transition region, and $L L$ and $U L$ are folded and unfolded baselines, respectively.

$$
F_{\mathrm{U}}=L L+\frac{U L-L L}{1+e^{\left(T_{\mathrm{m}}-T\right) / c}}
$$

Computational Modeling. The starting points for computational analysis of $\mathrm{NADH}$-dependent 3-oxovalerate reduction catalyzed by $\mathrm{HBDH}$ were chains $\mathrm{D}$ and $\mathrm{C}$ of $\mathrm{PaHBDH}$ and $\mathrm{AbHBDH}$ crystal structures, respectively. Employing only the monomers considerably reduces computational costs and is expected to have no effect on the final results, since the nearest subunit in each enzyme tetramer is over $15 \AA$ away from the substrates in a given active site, and no evidence exists for cooperativity in the HBDHs studied here. The structures were further refined by removing all water molecules found more than $5 \AA$ from any enzyme atom. MolProbity ${ }^{36}$ was used to check for residue flips and for protonation states of histidine residues (Table S1). All other residues were charged as predicted by PROPKA $3.1^{41}$ assuming $\mathrm{pH}=7.0$. The substrate 3 -oxovalerate was repositioned manually in the active site to minimize steric clashes and align for hydride transfer from $\mathrm{NADH}$ and for proton transfer from the catalytic tyrosine. The simulation system was modeled using the CHARMM36 force field ${ }^{42}$ in combination with the TIP3P water model. ${ }^{43}$ Parameters for 3oxovalerate were generated using $\mathrm{CGenFF}^{44}$ and for $\mathrm{NADH}$ they were obtained from Pavelites et al. ${ }^{45}$ A density-functional theory (DFT)-based QM/MM approach was used to explore the underlying reaction potential energy surface (PES), excluding thermal effects through proper configurational sampling. To alleviate the multiple-minima problem associated with such calculations, i.e., exploring the vast potential energy landscape of an enzyme-catalyzed reaction, calculations were 
repeated for 10 configurations generated via molecular dynamics (MD).

Molecular Dynamics. Classical MD simulations were set up using QwikMD ${ }^{46}$ and performed with NAMD2. ${ }^{47}$ The simulation box buffer was set to $15 \AA$ and $\mathrm{NaCl}$ concentration to $0.15 \mathrm{M}$. All backbone heavy atoms were restrained to their initial crystal position using a $1.0 \mathrm{kcal} / \mathrm{mol} / \AA^{2}$ harmonic restraint to prevent excessive fluctuations. The system was first subjected to an energy minimization followed by gradual heating to $10{ }^{\circ} \mathrm{C}$ over 134.4 ps. This was followed by a $10 \mathrm{~ns}$ simulation at $10{ }^{\circ} \mathrm{C}$ from which a total of 10 configurations were written out at $1 \mathrm{~ns}$ intervals for use as starting geometries for $\mathrm{QM} / \mathrm{MM}$ calculations.

QM/MM Calculations. QM/MM calculations were performed with ORCA 4.2.18 ${ }^{48}$ coupled with XTB 6.3.1. ${ }^{49}$ The QM region used in the calculations encompassed the nicotinamide nucleoside moiety of $\mathrm{NADH}, 3$-oxovalerate, and the side chains of the catalytic tyrosine and serine. An initial energy minimization was performed using tight-binding GFN2-XTB QM/MM. ${ }^{49}$ The mobile MM region included all residues and water molecules within $25 \AA$ of the $\mathrm{QM}$ atoms. In order to reduce the error resulting from an inadequate description of solvent reorganization from reactant to transition state in the static QM/MM approach, the initial minimization was performed at an approximate transition-state geometry by constraining the reactive distances to 1.35 and $1.25 \AA$ for the $\mathrm{C}-\mathrm{H}$ and $\mathrm{O}-\mathrm{H}$ bonds, respectively. To map the reactive PES, a systematic scan along the reacting coordinates was deemed impractical due to the number of bonds (4) involved in the reaction. Moreover, a scan along any one or two distances would not provide an adequate reaction coordinate and likely yield poor transition-state estimates. Instead, the option was for the nudge elastic band-climbing image (NEB-CI) method, which allows one to estimate the full minimum energy path (MEP) connecting the reactant and the product states while also yielding accurate estimates of transition states. Using a smaller mobile MM region which included residues within $3 \AA$ from the $\mathrm{QM}$ atoms, geometries of the reactant and product states were optimized and an approximate transition-state geometry located by NEB-CI. The QM region was described using a pure meta-GGA functional and minimally augmented double- $\zeta$ basis set, TPSS/ma-def2$\mathrm{SVP}^{50}$ which was found to be a good price/performance method, yielding similar MEPs to hybrid-DFT methods (see Results and Discussion) with substantial reduction in computational cost. It was noticed that the method consistently underestimates the activation barrier as previously reported; ${ }^{51}$ thus, it was used only for initial exploration of MEPs. D3 Becke-Johnson ${ }^{52}$ and geometric counter-poise corrections $^{53}$ were applied to correct for dispersion interactions and basis-set superposition error. Finally, the MEP was reoptimized at the M062X level of theory using the minimally augmented basis set ma-def2-SVP, which was shown to yield reliable barrier heights for hydrogen-transfer reactions. ${ }^{54,55}$ The RIJCOSX approximation was employed to speed up the Hartree-Fock exchange calculation. ${ }^{56}$ Approximate stationary points on the MEP were reoptimized via a microiterative approach. The QM region was first optimized at the M062X/ ma-def2-SVP level of theory in internal coordinates using the BFGS algorithm for 10 iterations, keeping the atoms of the environment frozen. This was followed by an optimization of the $25 \AA$ mobile MM region in Cartesian coordinates for 100 iterations using the L-BFGS algorithm, during which the QM atoms were kept frozen and described at the GFN2-XTB level of theory. The 10/100 approach was repeated until convergence. The Baker eigenvector-following algorithm was used for transition-state optimizations with a 50/100 iteration approach. An approximate hybrid Hessian was calculated for the reactive atoms at the beginning of each QM optimization. Frequency calculations were performed using the Partial Hessian Vibrational Analysis (PHVA) method $^{57}$ to confirm the nature of the stationary points and allow for estimation of zero-point energies and thermal corrections. Final single-point energies were calculated using M062X/ma-def2-TZVPP (RIJCOSX). We note that there is no gain in accuracy when using larger quadruple- $\zeta$ basis sets. ${ }^{55}$

\section{RESULTS AND DISCUSSION}

Initial Velocity Patterns and NADH Equilibrium Binding for $P a H B D H$ and $A b H B D H$. Initial velocity patterns for acetate reduction intersecting on the left of the $y$ axes (Figure S1) show that $\mathrm{PaHBDH}$ and $\mathrm{AbHBDH}$ follow a sequential mechanism and rule out a rapid equilibrium ordered addition of substrates to the enzymes. Data fitting to eq 1 yielded the kinetic constants summarized in Table S2. Furthermore, binding of $\mathrm{NADH}$ to $\mathrm{PaHBDH}$ was demonstrated by fluorescence spectroscopy (Figure S2), where data fitting to eq 2 yielded $K_{\mathrm{D}}=7 \pm 2 \mu \mathrm{M}$, while $\mathrm{NADH}$ binding to $A b \mathrm{HBDH}$ was shown by ITC (Figure S3), and data fitting to a single-site binding model (stoichiometry of $1: 1$ and no cooperativity) resulted in a $K_{\mathrm{D}}=14 \pm 8 \mu \mathrm{M}$. These observations are compatible with the steady-state ordered kinetic mechanism also reported for Rhodopseudomonas spheroides and Pseudomonas lemoignei $\mathrm{HBDH}$ where $\mathrm{NADH}$ is the first substrate to bind ${ }^{17,18}$ but do not rule out a random kinetic mechanism.

Primary Deuterium Kinetic Isotope Effects on Acetoacetate Reduction. The order of substrate binding in sequential mechanisms can be gleaned from the magnitude of the kinetic isotope effects on the specificity constant $k_{\text {cat }} / K_{\mathrm{M}}$ based on the dependence of the forward commitment factor $\left(C_{\mathrm{f}}\right)$ for one substrate on the saturation level of the other substrate. ${ }^{58}$ Primary deuterium kinetic isotope effects on $k_{\mathrm{cat}} /$ $K_{\mathrm{M}}{ }^{\mathrm{D}}\left(k_{\mathrm{cat}} / K_{\mathrm{M}}\right)$, for acetoacetate reduction by $\mathrm{PaHBDH}$ and $A b \mathrm{HBDH}$ were measured using $\mathrm{NADH}$ and NADD (Figure 1 ), and values are summarized in Table 1. For both enzymes, at saturating concentrations of the cosubstrate, ${ }^{\mathrm{D}}\left(k_{\text {cat }} / K_{\mathrm{M}}^{\mathrm{AcAc}}\right)$ are above unity but ${ }^{\mathrm{D}}\left(k_{\mathrm{cat}} / K_{\mathrm{M}}{ }^{\mathrm{NADH}}\right)$ are equal to unity within experimental error. This indicates that when the acetoacetate concentration is saturating, the $\mathrm{NADH}$ dissociation rate from the ternary complex is negligible in comparison with the rate of hydride transfer, drastically increasing $C_{\mathrm{f}}^{\mathrm{NADH}}$ and eclipsing ${ }^{\mathrm{D}}\left(k_{\text {cat }} / K_{\mathrm{M}}{ }^{\mathrm{NADH}}\right)$, a pattern consistent only with a steady-state ordered kinetic mechanism in which $\mathrm{NADH}$ is the first substrate to bind. ${ }^{58}$

Beyond the kinetic mechanism, the similar values of ${ }^{\mathrm{D}}\left(k_{\mathrm{cat}}\right)$ $K_{\mathrm{M}}^{\mathrm{AcAc}}$ ) and the primary deuterium kinetic isotope effect on $k_{\text {cat }}{ }^{\mathrm{D}} k_{\text {cat }}$, suggest $k_{\text {cat }}$ and $k_{\text {cat }} / K_{\mathrm{M}}{ }^{A c A c}$ report on the same step. Furthermore, the modest values of $\mathrm{PaHBDH}{ }^{\mathrm{D}} k_{\text {cat }}$ and ${ }^{\mathrm{D}}\left(k_{\mathrm{cat}}\right)$ $K_{\mathrm{M}}^{\mathrm{AcAc}}$ ) indicate hydride transfer is likely not rate limiting at 10 ${ }^{\circ} \mathrm{C}$, while values above 2 for $A b \mathrm{HBDH}^{\mathrm{D}} k_{\text {cat }}$ and ${ }^{\mathrm{D}}\left(k_{\mathrm{cat}} / K_{\mathrm{M}}{ }^{\mathrm{AcAc}}\right)$ point to chemistry being at least partially rate- limiting with the mesophilic enzyme. Our previous pre-steady-state kinetics results showed that neither enzyme displays a burst in product formation during approach to the steady state at this temperature. ${ }^{20}$ This is fully consistent with $A b \mathrm{HBDH}{ }^{\mathrm{D}} k_{\text {cat }}$ 

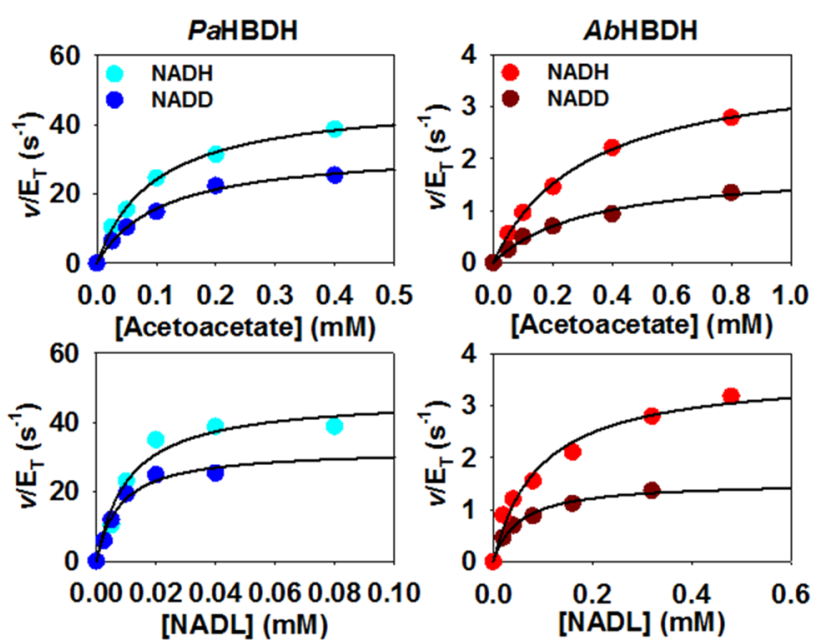

Figure 1. Primary deuterium kinetic isotope effects on acetoacetate reduction. Data points are mean \pm SE of triplicate measurements. Lines are best fit to eq 3. NADL is either NADH or NADD.

Table 1. Primary Deuterium Kinetic Isotope Effects on $\mathrm{PaHBDH}$ - and $\mathrm{A} b \mathrm{HBDH}-\mathrm{Catalyzed} \mathrm{Reduction} \mathrm{of}$ Acetoacetate

$\begin{array}{lcc}\text { isotope effect } & \mathrm{PaHBDH} \text { acetoacetate } & A b \mathrm{HBDH} \text { acetoacetate } \\ { }^{\mathrm{D}} k_{\text {cat }} & 1.46 \pm 0.04 & 2.2 \pm 0.1 \\ { }^{\mathrm{D}}\left(k_{\text {cat }} / K_{\mathrm{M}}^{\mathrm{AcAc}}\right) & 1.6 \pm 0.2 & 2.3 \pm 0.5 \\ { }^{\mathrm{D}}\left(k_{\text {cat }} / K_{\mathrm{M}}{ }^{\mathrm{NADH}}\right) & 1.1 \pm 0.4 & 1.2 \pm 0.3\end{array}$

and ${ }^{\mathrm{D}}\left(k_{\mathrm{cat}} / K_{\mathrm{M}}^{\mathrm{AcAc}}\right)$, but it requires that either an isotopeinsensitive step after acetoacetate binding and prior to hydride transfer be rate limiting for $\mathrm{PaHBDH}$ or the rates of chemistry and product release, though different, not be distinct enough to produce a burst. ${ }^{59}$

Primary Deuterium Kinetic Isotope Effects on 3Oxovalerate Reduction. To gain insight into the chemistry of $\mathrm{PaHBDH}$ and $\mathrm{AbHBDH}$, primary deuterium kinetic isotope effects for 3-oxovalerate reduction were measured (Figure 2) since this substrate is reduced more slowly by both enzymes ${ }^{20}$ which may help expose the chemical step. Due to a decrease in the already low $\mathrm{PaHBDH} K_{\mathrm{M}}$ values when 3-oxovalerate and NADD are used, data could be acquired only for concentrations near saturation for the coenzyme and 3oxovalerate; therefore, isotope effects solely on $k_{\text {cat }}$ were measured with the psychrophilic enzyme (Table 2). As predicted, ${ }^{\mathrm{D}} k_{\text {cat }}$ for $\mathrm{PaHBDH}$ increased to $2.15 \pm 0.03$,

Table 2. Kinetic Isotope Effects on $\mathrm{PaHBDH}$ - and AbHBDH-Catalyzed Reduction of 3-Oxovalerate

\begin{tabular}{lcc} 
isotope effect & $P a \mathrm{HBDH}$ 3-oxovalerate & $A b \mathrm{HBDH}$ 3-oxovalerate \\
${ }^{\mathrm{D}} k_{\text {cat }}$ & $2.15 \pm 0.03$ & $2.0 \pm 0.1$ \\
$\mathrm{D}^{\mathrm{D}}\left(k_{\text {cat }} / K_{\mathrm{M}}{ }^{3 \mathrm{OV}}\right)$ & & $2.2 \pm 0.3$ \\
$\mathrm{D}^{\mathrm{D}}\left(k_{\text {cat }} / K_{\mathrm{M}}{ }^{\mathrm{NADH}}\right)$ & & $2.0 \pm 0.5$ \\
$\mathrm{D}_{2} \mathrm{O} k_{\text {cat }}$ & $2.6 \pm 0.1$ & $1.34 \pm 0.04$ \\
$\mathrm{D}_{2} \mathrm{O}\left(k_{\text {cat }} / K_{\mathrm{M}}{ }^{3 \mathrm{OV}}\right)$ & & $1.4 \pm 0.2$ \\
$\mathrm{D}_{2} \mathrm{O}\left(k_{\text {cat }} / K_{\mathrm{M}}{ }^{\mathrm{NADH}}\right)$ & & $2.0 \pm 0.4$ \\
$\mathrm{D}_{2} \mathrm{O}\left(k_{\text {cat }}\right)_{\mathrm{D}}$ & $3.1 \pm 0.1$ & $3.5 \pm 0.1$ \\
$\mathrm{D}_{2} \mathrm{O}\left(k_{\text {cat }} / K_{\mathrm{M}}{ }^{3 \mathrm{OV}}\right)_{\mathrm{D}}$ & & $2.0 \pm 0.2$ \\
$\mathrm{D}_{2} \mathrm{O}\left(k_{\text {cat }} / K_{\mathrm{M}}{ }^{\mathrm{NADH}}\right)_{\mathrm{D}}$ & & $1.0 \pm 0.2$ \\
\hline
\end{tabular}

indicating that hydride transfer becomes more rate limiting with 3-oxovalerate. Interestingly, ${ }^{\mathrm{D}} k_{\text {cat }}$ and ${ }^{\mathrm{D}}\left(k_{\text {cat }} / K_{\mathrm{M}}{ }^{3 \mathrm{OV}}\right)$ for $A b \mathrm{HBDH}$ remained the same (Table 2), suggesting 3oxovalerate imparted no change in the rate-limiting step governing these two rate constants. However, ${ }^{\mathrm{D}}\left(k_{\text {cat }} / K_{\mathrm{M}}{ }^{\mathrm{NADH}}\right)$ increased significantly from its previous unity value with acetoacetate, which means 3-oxovalerate lowers $C_{\mathrm{f}}^{\mathrm{NADH}}$, a consequence of the kinetic mechanism becoming rapid equilibrium and/or random. ${ }^{58}$

Acid-Base Catalysis. To probe the role of acid-base catalysis in $\mathrm{PaHBDH}$ and $\mathrm{AbHBDH}$ reactions, $\mathrm{pH}$-rate profiles of steady-state parameters were determined for 3oxovalerate reduction (Figure S4). The $\mathrm{PaHBDH} k_{\text {cat }} k_{\text {cat }} /$ $K_{\mathrm{M}}{ }^{3 \mathrm{OV}}$, and $k_{\text {cat }} / K_{\mathrm{M}}{ }^{\mathrm{NADH}}$ profiles were fitted to eq 4 , describing abolition of activity at high $\left(k_{\text {cat }}\right.$ profile $)$ and low $\left(k_{\text {cat }} / K_{\mathrm{M}}\right.$ profiles) substrate concentrations upon deprotonation of a group with $\mathrm{p} K_{\mathrm{a}}=8.9 \pm 0.1$ (from the $k_{\text {cat }}$ profile), $7.2 \pm 0.2$ (from the $k_{\text {cat }} / K_{\mathrm{M}}{ }^{30 V}$ profile), and $7.7 \pm 0.1$ (from the $k_{\text {cat }} /$ $K_{\mathrm{M}}{ }^{\mathrm{NADH}}$ profile). The $\mathrm{p} K_{\mathrm{a}}=8.9 \pm 0.1$ is in the range of $\mathrm{p} K_{\mathrm{a}}$ values proposed for the conserved tyrosine and lysine residues in SDR catalytic triads. ${ }^{60}$ The $\mathrm{p} K_{\mathrm{a}}$ from $k_{\text {cat }} / K_{\mathrm{M}}{ }^{3 \mathrm{OV}}$ and that from $k_{\text {cat }} / K_{\mathrm{M}}{ }^{\mathrm{NADH}}$ are close enough that they might report on the same group whose ionization governs the second-order rate constants at low concentrations of the respective substrates, but it is not possible from the current data to hypothesize the identity of this group.

The $A b \mathrm{HBDH} k_{\mathrm{cat}} / K_{\mathrm{M}}{ }^{30 \mathrm{~V}}$ profile was fitted to eq 4 , describing abolition of activity at low concentrations of 3-

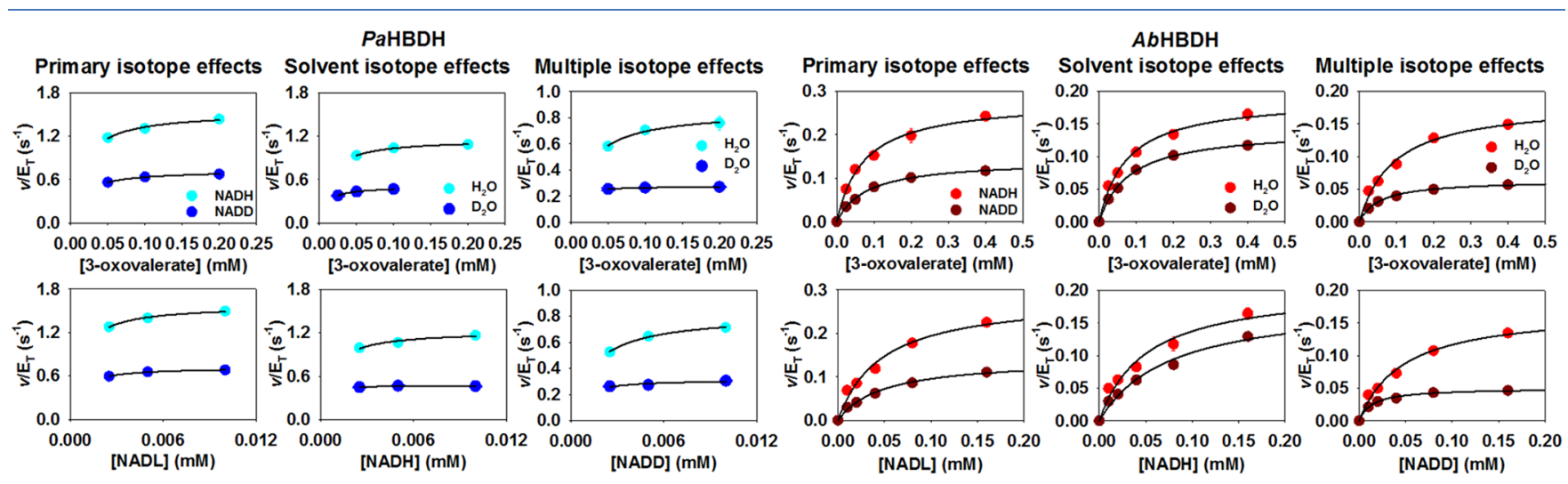

Figure 2. Primary, solvent, and multiple deuterium kinetic isotope effects on 3-oxovalerate reduction. Data points are mean \pm SE of triplicate measurements. Lines are best fit to eq 3. NADL is either NADH or NADD. 
oxovalerate upon deprotonation of a group with $\mathrm{p} K_{\mathrm{a}}=8.5 \pm$ 0.1. This eliminates the ionization of the substrate itself, as 3oxovalerate has no ionizable group in this $\mathrm{p} K_{\mathrm{a}}$ range, and does not rule out a role for the conserved catalytic-triad tyrosine or lysine residue. ${ }^{60}$ The $k_{\text {cat }} / K_{\mathrm{M}}{ }^{\mathrm{NADH}}$ profile is $\mathrm{pH}$ independent, indicating the $\mathrm{p} K_{\mathrm{a}}$ of any group whose protonation state might be relevant for activity at low $\mathrm{NADH}$ concentration lies outside the $\mathrm{pH}$ range tested. The $k_{\mathrm{cat}}$ is also $\mathrm{pH}$ independent, normally pointing to productive substrate binding to only one protonation state of the enzyme, resulting in a curvature in the $k_{\text {cat }} / K_{\mathrm{M}}$ profile, ${ }^{61}$ which is observed with $k_{\text {cat }} / K_{\mathrm{M}}{ }^{3 \mathrm{OV}}$.

Solvent Deuterium Kinetic Isotope Effects on 3Oxovalerate Reduction. The redox reaction catalyzed by $\mathrm{HBDH}$ involves necessarily a proton transfer to the substrate 3-carbonyl oxygen to yield the 3-hydroxyl group in the product (Scheme 1). ${ }^{1}$ To probe the contribution of proton transfer to 3-oxovalerate reduction kinetics, solvent deuterium kinetic isotope effects were determined (Figure 2), and the results are summarized in Table 2 . No solvent viscosity effect was detected for either enzyme in the presence of $7 \%$ glycerol (Figure S5), confirming the effects of $\mathrm{D}_{2} \mathrm{O}$ on the reaction rates are indeed isotope effects and not a consequence of increased medium viscosity. Again, for $\mathrm{PaHBDH}$, only isotope effects on $k_{\text {cat }}$ could be measured, and a ${ }^{\mathrm{D}_{2} \mathrm{O}} k_{\text {cat }}=2.6 \pm 0.1$ indicates that one or more proton transfers are at least partially rate limiting.

For $A b \mathrm{HBDH},{ }^{\mathrm{D}_{2} \mathrm{O}} k_{\text {cat }}$ and ${ }^{\mathrm{D}_{2} \mathrm{O}}\left(k_{\text {cat }} / K_{\mathrm{M}}{ }^{3 \mathrm{OV}}\right)$ are smaller than 2. While these values make it tempting to consider a negligible kinetic contribution from the proton transfer steps, it should be pointed out that it is possible for solvent isotope effects of this magnitude to reflect rate-limiting proton transfers. For instance, if two or more proton transfers give rise to the solvent isotope effect but at least one of them produces a large enough inverse isotope effect, the overall observed isotope effect will be smaller than the largest individual normal one. ${ }^{62,63}$ Surprisingly, ${ }^{\mathrm{D}_{2} \mathrm{O}}\left(k_{\text {cat }} / K_{\mathrm{M}}{ }^{\mathrm{NADH}}\right)=2.0 \pm 0.4$, reflecting a decrease in $C_{\mathrm{f}}^{\mathrm{NADH}}$, similar to what was observed for the $\mathrm{D}\left(k_{\text {cat }} / K_{\mathrm{M}}{ }^{\mathrm{NADH}}\right)$ with 3-oxovalerate as substrate.

Multiple Deuterium Kinetic Isotope Effects on 3Oxovalerate Reduction. Measuring the impact of a deuterated substrate on a separate isotope effect can inform the order of chemical events taking place in the active site. ${ }^{64}$ For $\mathrm{PaHBDH}$ and $\mathrm{AbHBDH}$ the primary deuterium kinetic isotope effects on 3-oxovalerate reduction are all equal to or larger than 2 (Table 2), meaning NADD imposes a considerable increase in the activation energy for hydride transfer. Therefore, the solvent kinetic isotope effects measured with $\mathrm{NADD}$ instead of $\mathrm{NADH}$ will increase from their original values if both proton and hydride transfers occur in the same transition state since the hydride transfer energy barrier is higher due to the use of NADD. Conversely, they will be smaller than their original values if proton and hydride transfers take place in separate steps because the proton transfer energy barrier is now less kinetically significant than it was with NADH. ${ }^{64}$ Multiple isotope effects for $\mathrm{PaHBDH}$ and $A b \mathrm{HBDH}$ were measured as solvent isotope effects with NADD as coenzyme (Figure 2) and are summarized in Table 2. For $\mathrm{PaHBDH}{ }^{\mathrm{D}_{2} \mathrm{O}}\left(k_{\text {cat }}\right)_{\mathrm{D}}=3.1 \pm 0.1$ increased from ${ }^{\mathrm{D}_{2} \mathrm{O}} k_{\text {cat }}=$ $2.6 \pm 0.1$, consistent with a single transition state involving a hydride transfer and a proton transfer, the latter likely to be protonation of the 3-carbonyl oxygen of 3-oxovalerate.

For $A b \mathrm{HBDH}^{\mathrm{D}_{2} \mathrm{O}}\left(k_{\text {cat }}\right)_{\mathrm{D}}=3.5 \pm 0.1$ and ${ }^{\mathrm{D}_{2} \mathrm{O}}\left(k_{\text {cat }} / K_{\mathrm{M}}{ }^{3 \mathrm{OV}}\right)_{\mathrm{D}}=$ $2.0 \pm 0.2$ are also larger than ${ }^{\mathrm{D}_{2} \mathrm{O}} k_{\text {cat }}=1.34 \pm 0.04$ and
$\mathrm{D}_{2} \mathrm{O}\left(k_{\text {cat }} / K_{\mathrm{M}}{ }^{3 \mathrm{OV}}\right)=1.4 \pm 0.2$, respectively, consistent with a concerted mechanism for proton and hydride transfers. Intriguingly, $\mathrm{D}_{2} \mathrm{O}\left(k_{\text {cat }} / K_{\mathrm{M}}{ }^{\mathrm{NADH}}\right)_{\mathrm{D}}$ reduces to unity, perhaps suggesting that $k_{\mathrm{cat}} / K_{\mathrm{M}}{ }^{\mathrm{NADH}}$ involves a separate proton transfer given the considerable values of ${ }^{\mathrm{D}}\left(k_{\text {cat }} / K_{\mathrm{M}}^{\mathrm{NADH}}\right)$ and ${ }^{\mathrm{D}_{2} \mathrm{O}}\left(k_{\text {cat }}\right)$ $\left.K_{\mathrm{M}}^{\mathrm{NADH}}\right)$. While the concerted or stepwise nature of hydride and proton transfers had not been previously investigated for HBDHs, a concerted mechanism has been proposed for Mycobacterium tuberculosis $\beta$-ketoacyl-acyl carrier protein reductase, another SDR catalyzing the reduction of 3oxothioesters in fatty acid biosynthesis. ${ }^{65}$

Crystal Structures of NAD ${ }^{+}$:Substrate-Bound $\mathrm{PaHBDH}$ and $A b \mathrm{HBDH}$. To investigate the structural underpinnings of $\mathrm{PaHBDH}$ and $\mathrm{AbHBDH}$ catalysis with acetoacetate (AcAc) and 3-oxovalerate $(3 \mathrm{OV})$, the crystal structures of the ternary complexes $\mathrm{PaHBDH}: \mathrm{NAD}^{+}$:AcAc, $A b \mathrm{HBDH}: \mathrm{NAD}^{+}$:AcAc, $\mathrm{PaHBDH}: \mathrm{NAD}^{+}: 3 \mathrm{OV}$, and $A b \mathrm{HBDH}: \mathrm{NAD}^{+}: 3 \mathrm{OV}$ were solved with data to $1.3,1.9,1.84$, and $1.9 \AA$ resolution, respectively. Data processing and refinement statistics are listed in Tables S3 and S4. Both $\mathrm{PaHBDH}$ structures have four molecules in the asymmetric units, which with crystallographic symmetry form two tetramers. The $A b \mathrm{HBDH}: \mathrm{NAD}^{+}: \mathrm{AcAc}$ and $A b \mathrm{HBDH}: \mathrm{NAD}^{+}: 3 \mathrm{OV}$ structures have one and six molecule(s) in the asymmetric unit, respectively, which with crystallographic symmetry also form tetramers. The tetrameric quaternary structure is common among $\mathrm{HBDHs}^{12-16}$ and SDRs in general. ${ }^{2}$ This quaternary arrangement seems to be present in solution as probed by analytical gel filtration (Figure S6) and is supported in crystallo by PISA ${ }^{66}$ analysis of the structures, which calculates a buried surface area of $15270 \AA^{2}$ (Figure S7). $F_{\text {obs }}-F_{\text {calc }}$ maps show clear density for $\mathrm{NAD}^{+}$and either acetoacetate or 3-oxovalerate in the relevant structures (Figure S8). In $\mathrm{PaHBDH}: \mathrm{NAD}^{+}: \mathrm{AcAc}$, two conformations of acetoacetate are modeled, and in $A b \mathrm{HBDH}: \mathrm{NAD}^{+}: 3 \mathrm{OV}$, two conformations of $\mathrm{NAD}^{+}$and/or 3-oxovalerate are modeled in some monomers (Figure S8).

Each monomer in the four structures displays the same overall fold previously reported for other HBDHs, with a Rossmann fold motif upon which the coenzyme binds, and the substrate binding on top of the coenzyme. ${ }^{12-15}$ Superimposition of a representative monomer from the $\mathrm{PaHBDH}$ and $A b \mathrm{HBDH}$ structures shows only minor differences in the overall topology between the different enzymes (Figure 3A). The largest root-mean-square deviation (RMSD) following comparison of the four complexes with each other is $1.25 \AA$ over 255 residues (between $\mathrm{PaHBDH}: \mathrm{NAD}^{+}: \mathrm{AcAc}$ and $\left.A b \mathrm{HBDH}: \mathrm{NAD}^{+}: 3 \mathrm{OV}\right)$. Both enzymes have a large flexible loop close to the active site. In several monomers of the two $\mathrm{PaHBDH}$ structures, the electron density was too disordered for some or all of the loop (residues $\sim 196-222$ ) to be modeled. The equivalent loop (residues $\sim 192-216$ ) in the $A b \mathrm{HBDH}$ structures was also disordered but could be modeled in most chains. The structure of $A b \mathrm{HBDH}$ in complex with $\mathrm{NAD}^{+}$and acetoacetate analyzed by the $B$ factor shows this region of the protein is indeed flexible and mobile (Figure 3B). Interestingly, one of the active-site residues in $\mathrm{PaHBDH}$, Gln202, is located on this loop, and therefore, the interaction between $\mathrm{Gln} 202$ and the substrate (acetoacetate/3-oxovalerate) may be transient.

Comparison between the structures of $\mathrm{PaHBDH}$ and $A b \mathrm{HBDH}$ with the same ligand shows the active-site architecture of the psychrophilic and mesophilic orthologues is similar with all but one of the residues conserved (Figure 

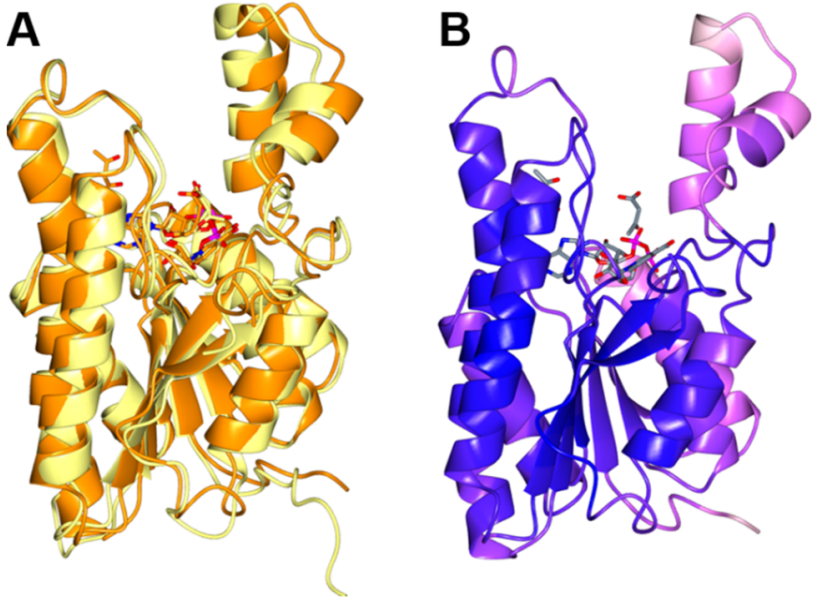

Figure 3. Structure of $\mathrm{PaHBDH}$ and $\mathrm{AbHBDH}$ monomers. (A) Superimposition of representative monomers of $\mathrm{PaHBDH}$ :NA$\mathrm{D}^{+}: \mathrm{AcAc}$ (yellow) and $A b \mathrm{HBDH}: \mathrm{NAD}^{+}: \mathrm{AcAc}$ (orange). (B) Structure of $A b \mathrm{HBDH}: \mathrm{NAD}^{+}: \mathrm{AcAc}$ colored by $B$-factor from low (dark blue) to high (white) with ligands in gray. In both panels, the protein is shown in the ribbon representation and the ligands as sticks.

S9A and S9B). Likewise, comparison of each enzyme binding to acetoacetate or 3-oxovalerate shows the positions of the active-site residues are essentially identical (Figure S9C and S9D), suggesting there is no requirement for repositioning of residues to accommodate the larger substrate. As proposed for other HBDHs, ${ }^{12,13}$ acetoacetate is held in place by polar contacts involving its carboxylate group and the side chains of conserved residues Gln202/197, Gln99/95, and Lys158/153 in $\mathrm{PaHBDH} / \mathrm{AbHBDH}$ (Figure 4 and Figure S10A). In the four complexes, the catalytic tyrosine (Tyr161/156 in $\mathrm{PaHBDH} / \mathrm{AbHBDH}$ ) donates a hydrogen bond to the carbonyl oxygen of the substrate and is likely the catalytic acid. It is worth noting that in the majority of the $\mathrm{PaHBDH}$ monomers in complex with either substrate, this interaction is unusually close $(\sim 2.2 \AA)$, whereas in the ligand complexes with $A b \mathrm{HBDH}$ the hydrogen-bond distance is in the normal range. The nicotinamide moiety of $\mathrm{NAD}^{+}$is anchored solely by polar contacts between its amide group and the main chain atoms (both carbonyl oxygen and amino groups) of Val194/189 in $\mathrm{PaHBDH} / \mathrm{AbHBDH}$ in such a way that if the reduced coenzyme were bound the $\mathrm{C}_{4}$-proS hydrogen would face the substrate carbonyl carbon from a plane that would ultimately result in formation of the $(R)$-enantiomer after hydride transfer. The hydride donor-acceptor distances are shorter (typically $3.2-3.3 \AA$ ) in the monomers of both $\mathrm{PaHBDH}$ structures compared to the $A b \mathrm{HBDH}$ structures (typically 3.4-3.8 $\AA$ ). The methyl group of acetoacetate and the ethyl group of 3-oxovalerate (the terminal carbon) form what would appear to be unfavorably close contacts with Ser148/143 and His 150/Asn 145 in $\mathrm{PaHBDH} / \mathrm{AbHBDH}$. This might be due to the fact that these are dead-end complexes. The differences in nicotinamide ring electrostatics between $\mathrm{NAD}^{+}$and $\mathrm{NADH}$ might lead to subtle conformational changes in the active site to alleviate these unfavorable interactions.

In HBDHs, ternary complex formation triggers a large opento-closed conformational change involving the substratebinding region to bring active-site residues into contact with the substrate. ${ }^{15,67}$ The crystal structures of Pseudomonas fragi $\mathrm{HBDH}: \mathrm{NAD}^{+}$binary complex ${ }^{67}$ and $\mathrm{HBDH}_{\mathrm{NAD}}{ }^{+}:(S)-3-$ hydroxybutyrate ternary complex ${ }^{15}$ exemplify this open-toclosed conformational switch. Furthermore, mutagenesis studies demonstrated the importance of residues Gln94, His144, and Gln196 in interacting with the substrate for binding and catalysis in addition to the confirmation of the essential role of the conserved Ser-Tyr-Lys catalytic triad. ${ }^{15}$ An overlay of representative monomers of $\mathrm{PaHBDH}: \mathrm{NAD}^{+}: \mathrm{AcAc}$ and $A b \mathrm{HBDH}: \mathrm{NAD}^{+}$:AcAc with $P$. fragi $\mathrm{HBDH}: \mathrm{NAD}^{+}:(S)-3-$ hydroxybutyrate (Figure $\mathrm{S} 10 \mathrm{~B}$ ) resulted in $\mathrm{C} \alpha \mathrm{RMSDs}$ of 1.86 and $3.99 \AA$, respectively. Active-site residues interacting with

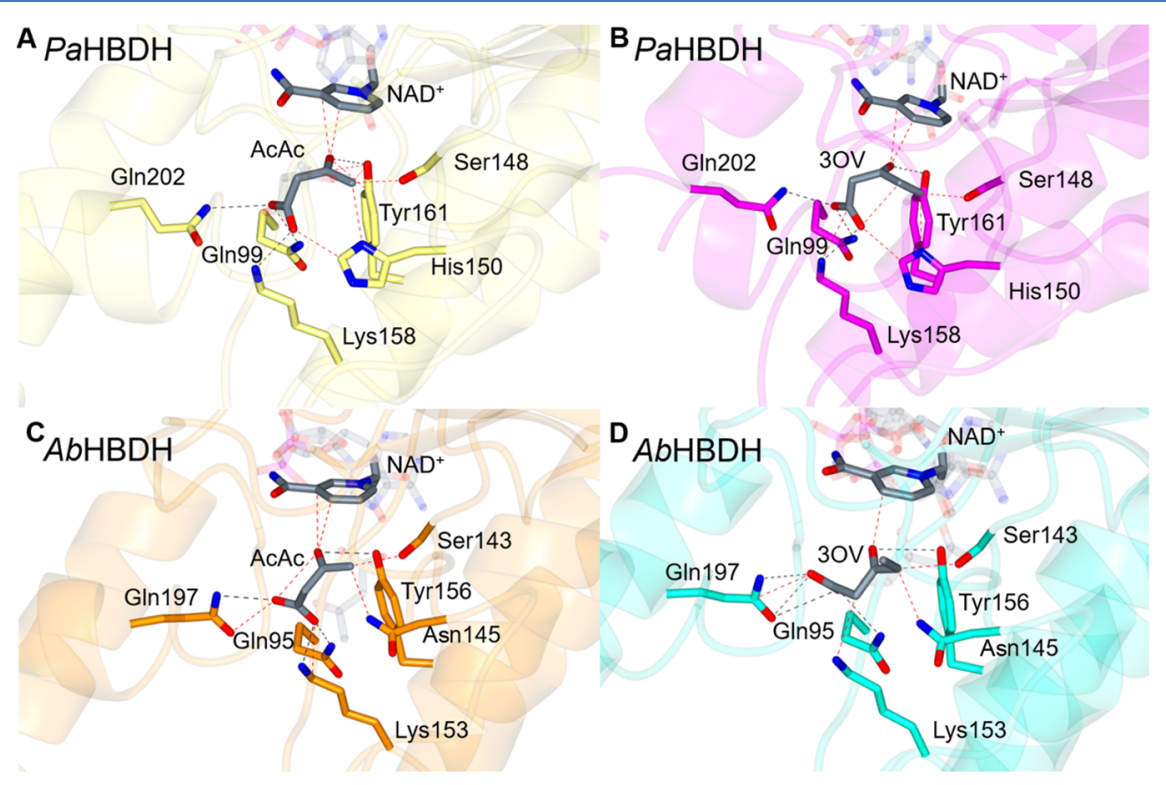

Figure 4. Active sites of $\mathrm{PaHBDH}$ and $\mathrm{AbHBDH}$. Adenosine diphosphate moiety of $\mathrm{NAD}^{+}$has been omitted for clarity. (A) $\mathrm{PaHBDH}: \mathrm{NAD}^{+}: \mathrm{AcAc}$, (B) PaHBDH:NAD ${ }^{+}: 3 \mathrm{OV}$, (C) AbHBDH:NAD ${ }^{+}: \mathrm{AcAc}$, and (D) AbHBDH:NAD $\mathrm{HOV}^{+}$. Active-site residues and ligands are shown in stick representation with oxygen depicted in red, nitrogen in blue, and carbon of the active-site residues in either yellow, magenta, orange, or cyan and of ligands in gray. Black dashed lines indicate hydrogen-bond interactions, and red dashed lines show unfavorable close contacts. 

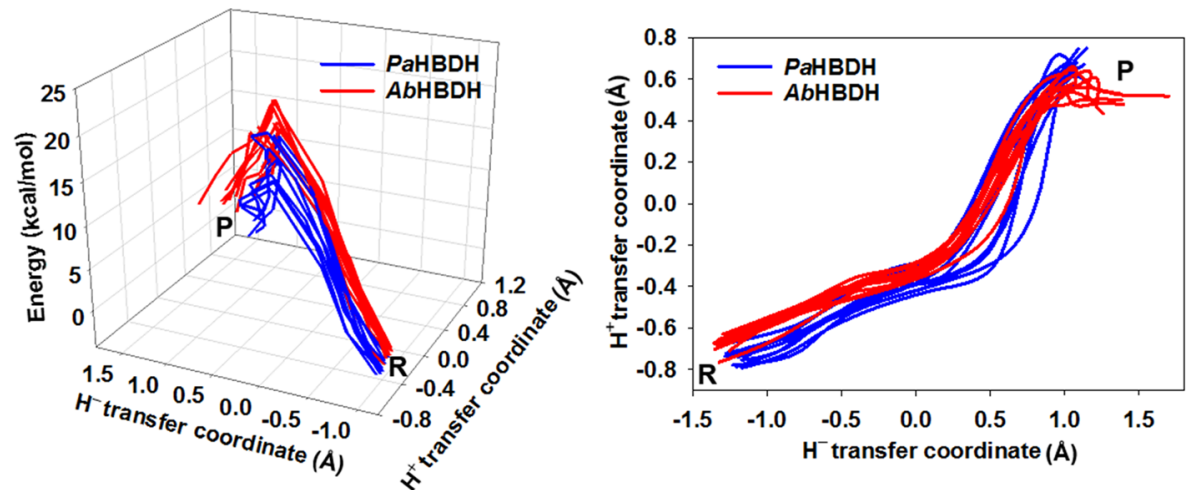

Figure 5. M06-2X/ma-def2-SVP-optimized MEPs for 3-oxovalerate reduction by $\mathrm{PaHBDH}$ and $\mathrm{AbHBDH}$. (Left) $3 \mathrm{D}$ plot including the relative energy profile along the MEPs. (Right)MEPs are projected onto the hydride transfer coordinate, defined as donor-hydride distance-acceptorhydride distance, and proton transfer coordinate, defined as donor-proton distance-acceptor-proton distance. Minima corresponding to reactant and product states are denoted by $\mathrm{R}$ and $\mathrm{P}$, respectively.

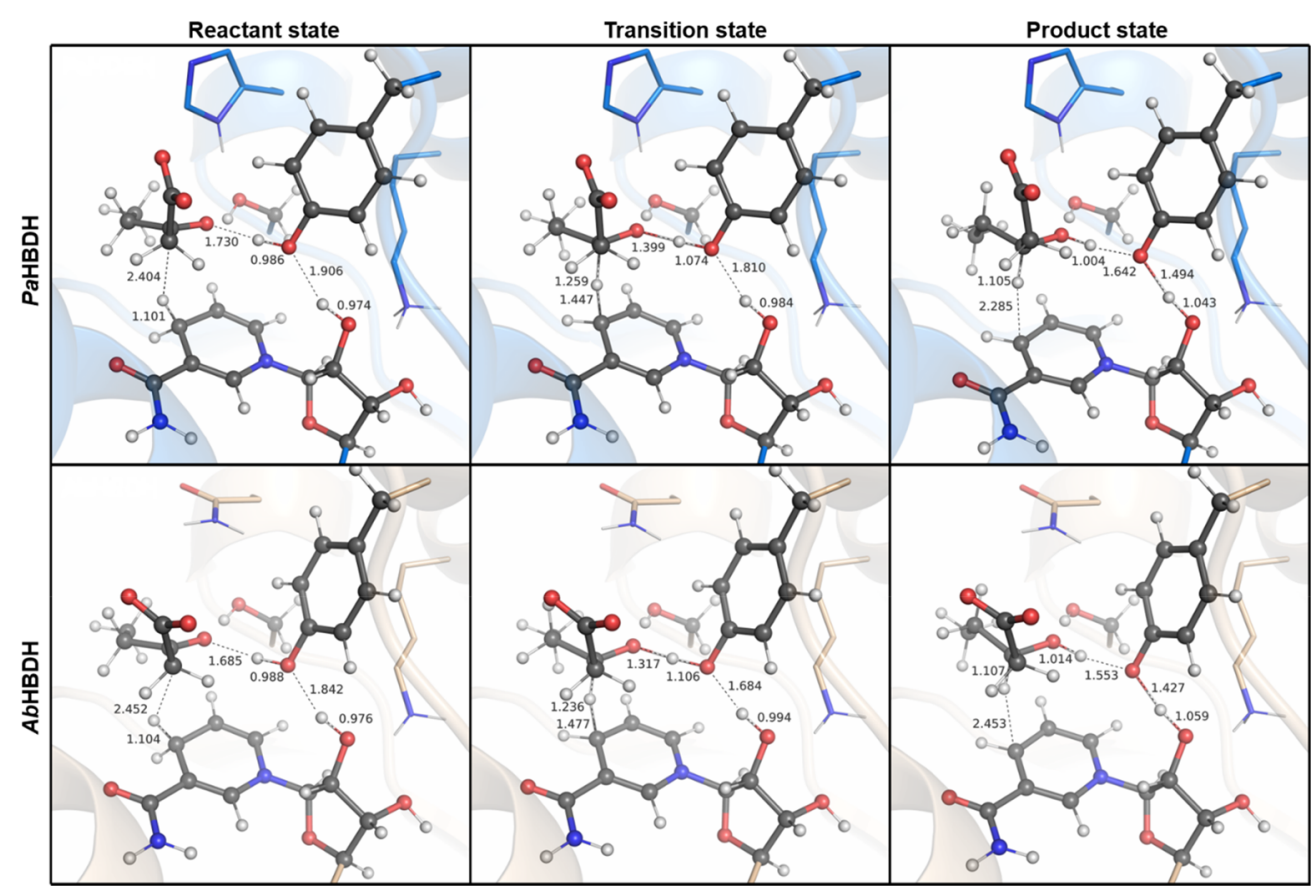

Figure 6. Stationary points along the reaction coordinate for $\mathrm{PaHBDH}$ - and $\mathrm{AbHBDH}$-catalyzed reduction of 3-oxovalerate. Distances are averages of 10 replicates optimized with the dual-level M06-2X/ma-def2-SVP/GFN2-XTB. Mean distances accompanied by their standard error of the mean are shown in Table S5. MM region is depicted in ribbon and stick models, while QM region is shown as ball-and-stick.

the substrate are conserved (except for Asn145 in AbHBDH) and in strikingly similar conformations as their counterparts in P. fragi $\mathrm{HBDH}: \mathrm{NAD}^{+}:(S)-3$-hydroxybutyrate (Figure S10C), suggesting they have equivalent catalytic roles in the three orthologues.

QM/MM Calculations on 3-Oxovalerate Reduction. While extensive free-energy calculations are crucial for obtaining a complete picture of enzyme reactions, the computational cost associated with thermal averaging of large condensed-phase systems limits its use to semiempirical QM methods. Although these allow for the rapid exploration of the PES, the PES itself can be qualitatively inaccurate and lead to dubious mechanistic conclusions. ${ }^{68}$ This is supported by calculations carried out here, which demonstrate the semiempirical GFN2-XTB, AM1, and PM3 methods significantly deviate from more rigorous DFT methods in describing the shape of the PES for the studied reaction (Figure S11). Hence we adopted the approach described above in Materials and Methods. The mechanism of 3-oxovalerate reduction by $\mathrm{PaHBDH}$ and $\mathrm{AbHBDH}$ was probed using a computational DFT-based QM/MM NEB approach. Acetoacetate was not considered here since the chemical step for this substrate is not rate limiting for $\mathrm{PaHBDH}$. For each enzyme, $10 \mathrm{MEPs}$ connecting the reactant and product states were initially optimized at the TPSS/ma-def2-SVP level of theory. To eliminate bias toward a particular initial pathway and to check for potential competing pathways, we initiated NEB optimizations from three distinct starting points: synchronous hydride and proton transfer, proton transfer followed by hydride transfer, and hydride transfer followed by proton transfer. As shown in Figure S12, the NEB calculations from three starting paths converge to the same MEP, indicating either there are no competing mechanistic pathways, or they pass through a higher reaction barrier and have no appreciable 
Table 3. Activation Parameters for 3-Oxovalerate Reduction by $\mathrm{PaHBDH}$ and $\mathrm{AbHBDH}$

\begin{tabular}{|c|c|c|c|c|}
\hline enzyme $\backslash$ parameter ${ }^{a, b}$ & $\Delta H^{\ddagger}$ (calculated) & $\Delta H^{\ddagger}$ (experiment) & $\Delta G^{\ddagger}($ calculated $)$ & $\Delta G^{\ddagger}$ (experiment) \\
\hline PaHBDH & $16.1 \pm 0.6(13.5)$ & $9.9 \pm 0.3$ & $18.4 \pm 0.6(15.9)$ & $16 \pm 0.4$ \\
\hline$A b \mathrm{HBDH}$ & $19.9 \pm 0.7(16.1)$ & $13.8 \pm 0.3$ & $21.9 \pm 0.7(17.8)$ & $17.4 \pm 0.3$ \\
\hline$\Delta(A b \mathrm{HBDH}-P a \mathrm{HBDH})$ & $3.8 \pm 0.9$ & $3.9 \pm 0.4$ & $3.5 \pm 1$ & $1.4 \pm 0.5$ \\
\hline
\end{tabular}

${ }^{a}$ Calculated parameters are mean \pm SD of 10 replicates. Exponential averages are shown in brackets. ${ }^{b}$ Experimental parameters reported for reactions at $10^{\circ} \mathrm{C}^{20}$
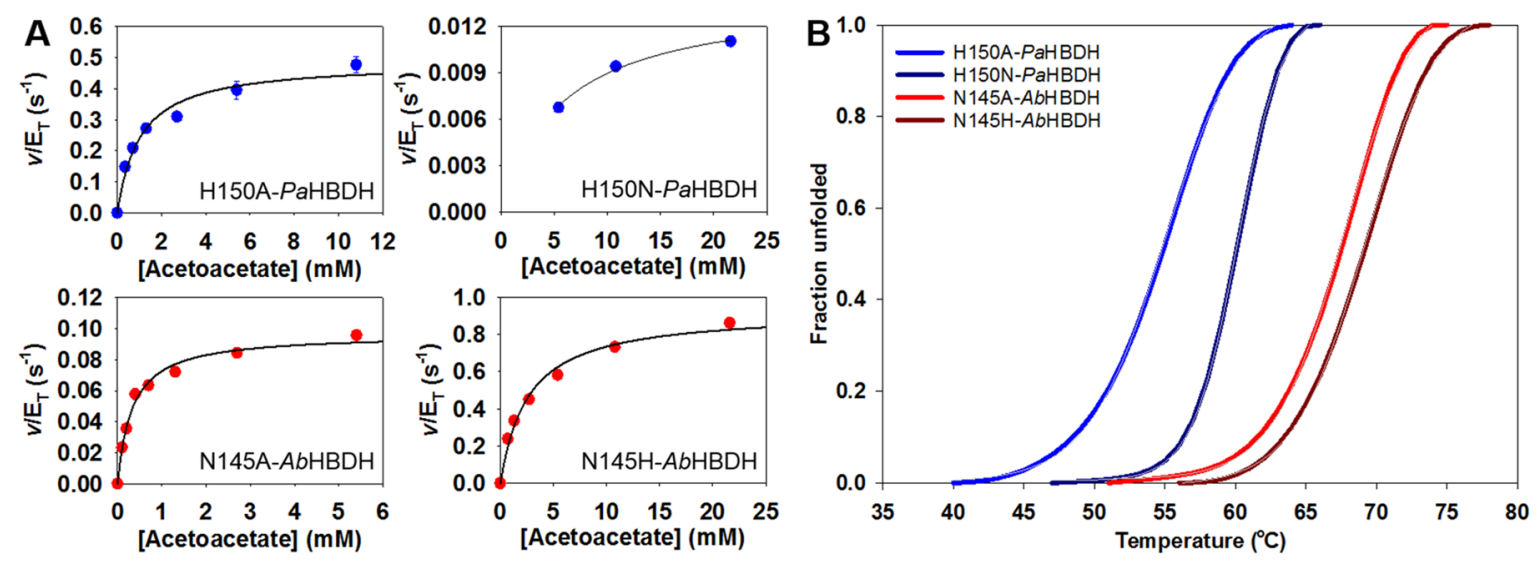

Figure 7. Analysis of HBDH mutants. (A) Steady-state kinetics of acetoacetate reduction catalyzed by $\mathrm{PaHBDH}$ and $\mathrm{AbHBDH}$ mutants. Lines of best fit to eq 3 are shown in black. (B) DSF-based denaturation of $\mathrm{PaHBDH}$ and $\mathrm{AbHBDH}$ mutants. Lines of best fit to eq 5 are in gray.

barrier separating them from the optimized MEP. MEPs were then reoptimized at the M06-2X/ma-def2-SVP level of theory (Figure 5). The reaction is shown to be concerted but asynchronous for both $\mathrm{HBDH}$ orthologues, with hydride transfer more advanced than protonation of the carbonyl oxygen at the transition state. The concerted character of the reaction is in agreement with the experimental multiple kinetic isotope effects.

Average reactive distances for reactant, product, and transition states (Figure 6 and Table S5) reveal only minor differences between the two enzymes. $A b \mathrm{HBDH}$ shows an overall slightly tighter $\mathrm{H}$-bond pattern than $\mathrm{PaHBDH}$, and proton transfer is more advanced at the transition state with the mesophilic enzyme. PHVA yielded only real frequencies for reactant and product states, and a single imaginary frequency in the range of $-654 \mathrm{~cm}^{-1}$ to $-879 \mathrm{~cm}^{-1}$ in the case of transition states, corresponding to concerted hydride transfer from $\mathrm{NADH}$ and proton transfer from the catalytic tyrosine.

Final energies calculated at the M06-2X/ma-def2-TZVPP level of theory and corrected for ZPE and thermal contributions yielded estimates of $\Delta H^{\ddagger}$ and $\Delta G^{\ddagger}$ (Table 3). M06-2X/ma-def2-TZVPP was chosen for its reported accuracy in modeling hydrogen-transfer reactions ${ }^{54}$ and for its excellent agreement with the rigorous double-hybrid density functional PWPB95 (Figure S11), which has been shown to predict reaction barrier heights accurately. ${ }^{69}$ The average $\Delta G^{\ddagger}$ are 18.4 and $21.9 \mathrm{kcal} \mathrm{mol}^{-1}$ for 3-oxovalerate reduction by $\mathrm{PaHBDH}$ and $A b \mathrm{HBDH}$, respectively. This is in reasonable agreement with experimental values, and captures the higher energy barrier reflected in the lower $k_{\text {cat }}$ for the mesophilic enzyme $\left(k_{\mathrm{cat}}=2.6 \pm 0.2 \mathrm{~s}^{-1}\right.$ for $\mathrm{PaHBDH}$ and $k_{\mathrm{cat}}=0.21 \pm 0.01 \mathrm{~s}^{-1}$ for $\mathrm{AbHBDH}) .^{20}$ The average values of $\Delta H^{\ddagger}$ calculated within the rigid-rotor harmonic oscillator approximation are overestimated, likely owing to the lack of proper thermal sampling of enzyme and solvent configurations. Nonetheless, the calculated average difference in $\Delta H^{\ddagger}$ between the two HBDHs is identical, within statistical error, to the experimental difference in $\Delta H^{\ddagger}$. In addition, the reported exponential averages, as recommended by Cooper et al., ${ }^{70}$ are in reasonable agreement with experimental values, showing the computational model captures the distinct thermodynamics of activation found experimentally for $\mathrm{PaHBDH}$ and $\mathrm{AbHBDH} .^{20}$

In an attempt to start uncovering the origins of catalysis by $\mathrm{HBDH}$ and the different catalytic rates between $\mathrm{PaHBDH}$ and $A b \mathrm{HBDH}$, the energies of the stationary points were recalculated after setting all partial charges of the MM region to zero. As shown in Figure S13, setting the protein partial charges to zero leads to a considerable increase in the activation energies. Furthermore, the differences in activation energies between the $\mathrm{PaHBDH}$ - and $\mathrm{AbHBDH}$-catalyzed reactions disappear. These observations suggest that electrostatic stabilization of the transition state by the protein environment makes a significant contribution to $\mathrm{HBDH}$ catalysis, and is likely the origin of the distinct catalytic rates between the two orthologues, although more in-depth studies are needed to explore this hypothesis further.

Kinetic Analysis of PaHBDH and AbHBDH Mutants. The active sites of $\mathrm{PaHBDH}$ and $\mathrm{AbHBDH}$ diverge only in one amino acid position: His 150 in $\mathrm{PaHBDH}$ is equivalent to Asn145 in $A b \mathrm{HBDH}$ (Figure S9A and S9B). P. fragi and Pseudomonas putida HBDHs have a histidine in the equivalent position, and its mutation to alanine resulted in a 14-fold reduction in $k_{\text {cat }}$ and a 28 -fold increase in $K_{\mathrm{M}}$ (P. fragi) and in an 8-fold reduction in $k_{\text {cat }}$ and a 23 -fold increase in $K_{\mathrm{M}}(P$. putida) for (R)-3-hydroxybutyrate during ( $R$ )-3-hydroxybutyrate oxidation. ${ }^{15,71}$ To assess the importance of this position in catalysis and interrogate its possible contribution to the kinetic differences between $\mathrm{PaHBDH}$ and $A b \mathrm{HBDH}$, single-site mutants H150A-PaHBDH, N145A-AbHBDH, H150N$\mathrm{PaHBDH}$, and $\mathrm{N} 145 \mathrm{H}-\mathrm{A} b \mathrm{HBDH}$ were generated, and purified. ESI-MS analysis indicated the purified proteins had the expected mass (Figure S14). HBDH variants followed 
Table 4. Steady-State Parameters for Acetoacetate Reduction Catalyzed by HBDH Mutants

\begin{tabular}{|c|c|c|c|}
\hline $\mathrm{HBDH}$ & $k_{\text {cat }}\left(\mathrm{s}^{-1}\right)$ & $K_{\mathrm{M}}^{\mathrm{AcAc}}(\mathrm{mM})$ & $K_{\mathrm{M}}^{\mathrm{NADH}}(\mathrm{mM})$ \\
\hline WT-PaHBDH ${ }^{a}$ & $30 \pm 1$ & $0.05 \pm 0.01$ & $0.0064 \pm 0.0002$ \\
\hline H150A-PaHBDH & $0.54 \pm 0.01$ & $1.0 \pm 0.2$ & $0.0023 \pm 0.0001$ \\
\hline $\mathrm{H} 150 \mathrm{~N}-\mathrm{PaHBDH}$ & $0.0140 \pm 0.0004$ & $<5400$ & $<0.08$ \\
\hline WT-AbHBDH ${ }^{a}$ & $3.4 \pm 0.1$ & $0.14 \pm 0.01$ & $0.07 \pm 0.01$ \\
\hline N145A-AbHBDH & $0.103 \pm 0.003$ & $0.33 \pm 0.04$ & $<0.005$ \\
\hline $\mathrm{N} 145 \mathrm{H}-A b \mathrm{HBDH}$ & $0.87 \pm 0.03$ & $2.6 \pm 0.4$ & $0.005 \pm 0.001$ \\
\hline
\end{tabular}

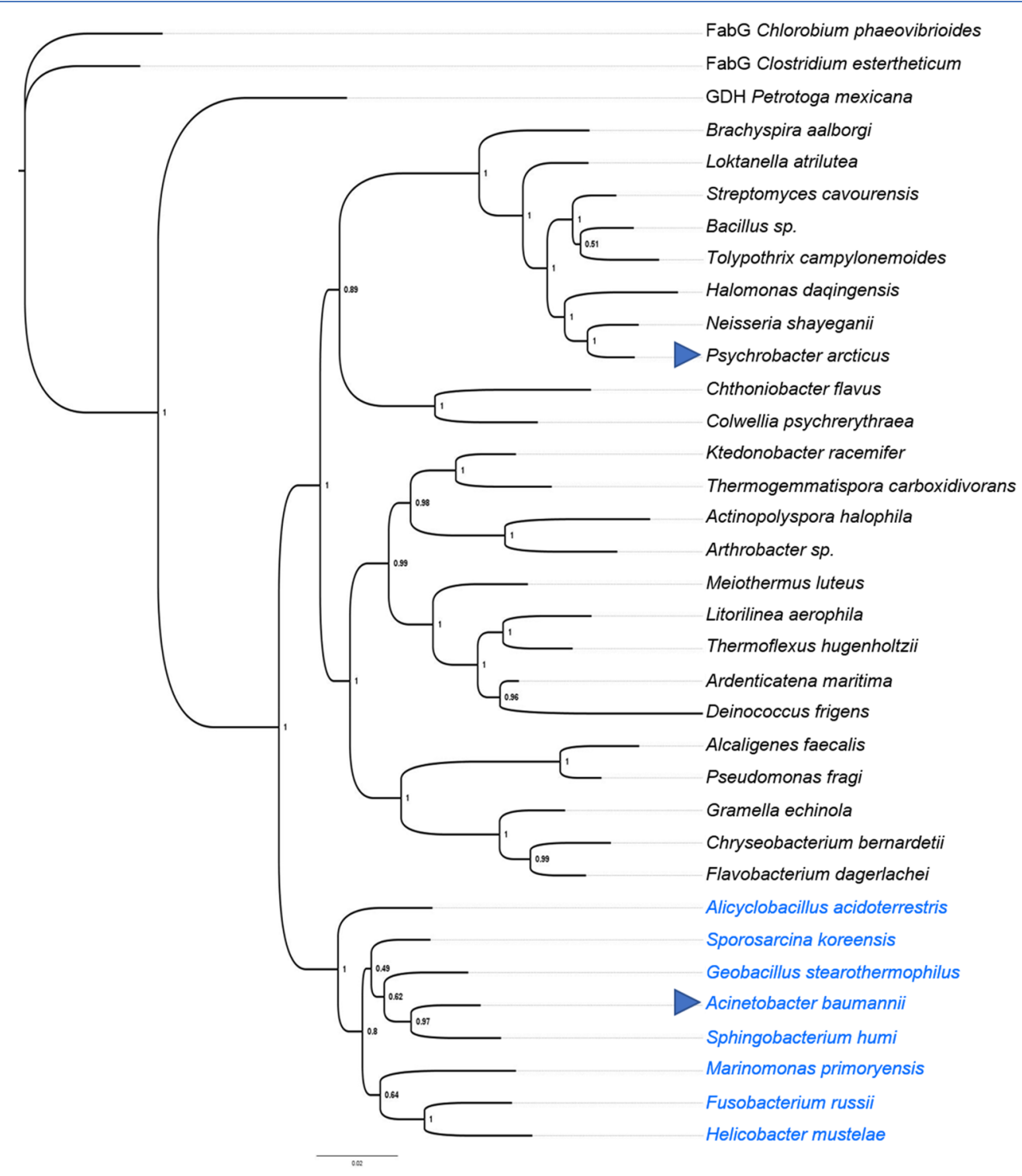

Figure 8. Cladogram of the calculated phylogenetic tree for HBDH. FabG and GDH sequences were used as out groups to root the tree. Asn145group is shown in blue. Numbers at the nodes represent the posterior probability. Arrowheads denote the species harboring PaHBDH and $\mathrm{A} b \mathrm{HBDH}$.

saturation kinetics for acetoacetate reduction (Figure 7A), but the N145A-AbHBDH $K_{\mathrm{M}}^{\mathrm{NADH}}$ decreased significantly in comparison with WT-AbHBDH, and only an upper limit was inferred, while the $\mathrm{H} 150 \mathrm{~N}-\mathrm{PaHBDH} k_{\text {cat }}$ was decreased to a point that rates at subsaturating substrate concentrations could not be accurately measured (Figure 7A and Figure S15).

A best fit of the steady-state kinetics data to eq 3 yielded the kinetic parameters shown in Table 4. H150A-PaHBDH produced a 55 -fold decrease in $k_{\text {cat }}$ and a 20 -fold increase in
$K_{\mathrm{M}}^{\mathrm{AcAc}}$ as compared with WT-PaHBDH, indicating a significant role for $\mathrm{His} 150$ in catalysis and acetoacetate binding. N145A-AbHBDH showed a 33-fold reduction in $k_{\text {cat }}$ but modest increase in $K_{\mathrm{M}}^{\mathrm{AcAc}}$ as compared with WT$A b \mathrm{HBDH}$, suggesting Asn145 plays a role in catalysis but not in acetoacetate binding. N145H-AbHBDH displayed an 18 -fold increase in $K_{\mathrm{M}}{ }^{\mathrm{AcAc}}$ but only a modest 3.9-fold decrease in $k_{\text {cat }}$ accompanied by a 14-fold decrease in $K_{\mathrm{M}}{ }^{\mathrm{NADH}}$, indicating that histidine can carry out the function of 
Asn 145 in $A b \mathrm{HBDH}$ catalysis to a large extent. Conversely, $\mathrm{H} 150 \mathrm{~N}-\mathrm{PaHBDH}$ is impaired by a 2142 -fold decrease in $k_{\text {cat }}$ suggesting that asparagine cannot perform the role of His 150 in $\mathrm{PaHBDH}$ catalysis. Previously, DSF-based protein denaturation established a $T_{\mathrm{m}}$ of 56.8 and $68.4{ }^{\circ} \mathrm{C}$ for $\mathrm{PaHBDH}$ and $A b \mathrm{HBDH}$, respectively. ${ }^{20} \mathrm{~N} 145 \mathrm{~A}-\mathrm{A} b \mathrm{HBDH}$ and $\mathrm{N} 145 \mathrm{H}-$ $A b \mathrm{HBDH}$ have $T_{\mathrm{m}}$ values of $67.7 \pm 0.1$ and $69.2 \pm 0.1{ }^{\circ} \mathrm{C}$ (Figure 7B), respectively, showing the mutations did not alter the thermal stability of the enzyme. Likewise, H150A$\mathrm{PaHBDH}$, with a $T_{\mathrm{m}}$ of $55.1 \pm 0.1{ }^{\circ} \mathrm{C}$, is as thermally stable as WT-PaHBDH. However, the $T_{\mathrm{m}}$ for $\mathrm{H} 150 \mathrm{~N}-\mathrm{PaHBDH}$ increased significantly to $61.0 \pm 0.1{ }^{\circ} \mathrm{C}$ (Figure 7B), indicating that Asn 150 led to thermal stabilization of the protein. Such stabilization might be detrimental to catalysis given the dramatic reduction in $\mathrm{H} 150 \mathrm{~N}-\mathrm{PaHBDH} k_{\text {cat }}$.

Phylogenetic Analysis of $\mathrm{HBDH}$. In order to evaluate the possible conservation of the $\mathrm{PaHBDH} \mathrm{His} 150 / \mathrm{AbHBDH}$ Asn 145 across $\mathrm{HBDHs}$ and the evolutionary relationship among these proteins, 32 different bacterial HBDH sequences from several bacterial phyla and comprising distinct environmental adaptation at the species level (thermophiles, mesophiles, psychrophiles, and halophiles) (Table S6) were aligned with concomitant generation of a phylogenetic tree. Only 8 of the HBDHs harbor an asparagine at the position equivalent to $A b \mathrm{HBDH}$ Asn145 (Figure S16), henceforth referred to as the Asn145 group. Interestingly, the Asn 145 group possesses strictly conserved residues Gly149, Phe150, and Gly152 ( $\mathrm{A} b \mathrm{HBDH}$ numbering). All remaining $24 \mathrm{HBDHs}$, henceforth dubbed the His 150 group, harbor a histidine on that position along with strictly conserved residues Ala154 and Ser155 ( $\mathrm{PaHBDH}$ numbering) at the positions corresponding to Gly149 and Phe150, respectively, while the position corresponding to Gly152 is not conserved (Figure S16). Interestingly, the phylogenetic tree clusters all Asn145-group HBDHs, suggesting a closer evolutionary relationship among these proteins, and they seem to have diverged early from His150-group HBDHs (Figure 8). Also intriguing is the wide scattering of HBDHs from thermophiles, mesophiles, psychrophiles, and halophiles across both groups, i.e., both Asn 145 and His 150 groups encompass HBDHs from bacteria that evolved to inhabit the four types of environment, indicating that these environmental adaptations are not reflected in $\mathrm{HBDH}$ primary sequences.

The conserved Gly149, Phe150, and Gly152 in Asn-145group HBDHs and Ala154 and Ser155 in His150-group HBDHs reside on a loop on top of the active site, albeit not directly contacting the substrate. Given the clustering of all HBDHs from the Asn 145 group in the phylogenetic tree and the distinct catalytic effects of Asn 145 and His150 mutations on $\mathrm{AbHBDH}$ and $\mathrm{PaHBDH}$, respectively, it is possible to hypothesize that this loop region may underpin the differences in catalytic rate constants observed between $A b \mathrm{HBDH}$ and $\mathrm{PaHBDH}$ and that these differences perhaps extend to Asn145-group and His150-group HBDHs in general. For instance, P. lemoignei and Alcaligenes faecalis $\mathrm{HBDH} \mathrm{s}^{11,18}$ belong to the His 150 group and have catalytic rates of acetoacetate reduction much higher than that of $A b \mathrm{HBDH} .^{20}$ Thus, the phylogenetic analysis could lay the foundation for future research into other $\mathrm{HBDH}$ orthologues from both groups to test this hypothesis and elucidate the exact role of the Gly149-Phe150-Gly152/ Ala154-Ser155 loops.

In summary, the combination of experimental multiple kinetic isotope effects, protein crystallography, and QM/MM calculations employed here provides the most detailed picture of the reaction catalyzed by $\mathrm{HBDH}$. The agreement between experimental and theoretical results lends support for the proposed mechanism where hydride and proton transfers occur in the same transition state. Furthermore, the kinetics, crystal structures, and $\mathrm{QM} / \mathrm{MM}$ calculations on the reduction of 3-oxovalerate, along with the mutagenesis and phylogenetic analysis described, may pave the way for engineering efforts of $\mathrm{HBDH}$ toward other non-native 3-oxocarboxylates.

\section{ASSOCIATED CONTENT}

\section{Supporting Information}

The Supporting Information is available free of charge at https://pubs.acs.org/doi/10.1021/acscatal.0c04736.

Further experimental and theoretical analyses of $\mathrm{HBDH}$ biochemistry, structure, QM/MM calculations, and phylogeny (PDF)

\section{AUTHOR INFORMATION}

\section{Corresponding Authors}

Johan Åqvist - Department of Cell and Molecular Biology, Biomedical Center, Uppsala University, Uppsala SE-751 24, Sweden; ○ orcid.org/0000-0003-2091-0610; Email: aqvist@xray.bmc.uu.se

Tracey M. Gloster - School of Biology, Biomedical Sciences Research Complex, University of St Andrews, St Andrews, Fife KY16 9ST, United Kingdom; Email: tmg@st-andrews.ac.uk

Rafael G. da Silva - School of Biology, Biomedical Sciences Research Complex, University of St Andrews, St Andrews, Fife KY16 9ST, United Kingdom; ㅇo orcid.org/0000-00021308-8190; Phone: +44 01334 463496; Email: rgds@standrews.ac.uk

\section{Authors}

Teresa F. G. Machado - School of Chemistry and School of Biology, Biomedical Sciences Research Complex, University of St Andrews, St Andrews, Fife KY16 9ST, United Kingdom

Miha Purg - Department of Cell and Molecular Biology, Biomedical Center, Uppsala University, Uppsala SE-751 24, Sweden; (1) orcid.org/0000-0003-4647-6103

Stephen A. McMahon - School of Biology, Biomedical Sciences Research Complex, University of St Andrews, St Andrews, Fife KY16 9ST, United Kingdom

Benjamin J. Read - School of Biology, Biomedical Sciences Research Complex, University of St Andrews, St Andrews, Fife KY16 9ST, United Kingdom

Verena Oehler - School of Biology, Biomedical Sciences Research Complex, University of St Andrews, St Andrews, Fife KY16 9ST, United Kingdom

Complete contact information is available at:

https://pubs.acs.org/10.1021/acscatal.0c04736

\section{Notes}

The authors declare no competing financial interest.

\section{ACKNOWLEDGMENTS}

This work was supported by the Engineering and Physical Sciences Research Council (EPSRC) [grant no. EP/L016419/ 1] via a CRITICAT Centre for Doctoral Training studentship to T.F.G.M., by the Wellcome Trust via a Research Career Development Fellowship to T.M.G., by the Biotechnology and Biological Sciences Research Council (BBSRC) (Grant BB/ 
M010996/1) via an EASTBIO Doctoral Training Partnership studentship to B.J.R., and by the Swedish Research Council and KAW Foundation grants to J.Å. X-ray diffraction data were collected at the Diamond Light Source in the United Kingdom. The authors are grateful to Reviewer 1 for insightful suggestions regarding interpretation of the $\mathrm{pH}$-rate profiles.

\section{REFERENCES}

(1) Bergmeyer, H. U.; Gawehn, K.; Klotzsch, H.; Krebs, H. A.; Williamson, D. H. Purification and Properties of Crystalline 3Hydroxybutyrate Dehydrogenase from Rhodopseudomonas Spheroides. Biochem. J. 1967, 102, 423-431.

(2) Persson, B.; Kallberg, Y. Classification and Nomenclature of the Superfamily of Short-Chain Dehydrogenases/Reductases (Sdrs). Chem.-Biol. Interact. 2013, 202, 111-115.

(3) Kavanagh, K. L.; Jornvall, H.; Persson, B.; Oppermann, U. Medium- and Short-Chain Dehydrogenase/Reductase Gene and Protein Families: The Sdr Superfamily: Functional and Structural Diversity within a Family of Metabolic and Regulatory Enzymes. Cell. Mol. Life Sci. 2008, 65, 3895-3906.

(4) Qin, F.; Qin, B.; Zhang, W.; Liu, Y.; Su, X.; Zhu, T.; Ouyang, J.; Guo, J.; Li, Y.; Zhang, F.; Tang, J.; Jia, X.; You, S. Discovery of a Switch between Prelog and Anti-Prelog Reduction toward HalogenSubstituted Acetophenones in Short-Chain Dehydrogenase/Reductases. ACS Catal. 2018, 8, 6012-6020.

(5) Gong, X.-M.; Qin, Z.; Li, F.-L.; Zeng, B.-B.; Zheng, G.-W.; Xu, J.H. Development of an Engineered Ketoreductase with Simultaneously Improved Thermostability and Activity for Making a Bulky Atorvastatin Precursor. ACS Catal. 2019, 9, 147-153.

(6) Ren, Q.; Ruth, K.; Thony-Meyer, L.; Zinn, M. Enatiomerically Pure Hydroxycarboxylic Acids: Current Approaches and Future Perspectives. Appl. Microbiol. Biotechnol. 2010, 87, 41-52.

(7) Iimori, T.; Shibasaki, M. Simple, Stereocontrolled Synthesis of $1 \beta$-Methylcarbapenem Antibiotics from 3(R)-Hydroxybutyric Acid. Tetrahedron Lett. 1986, 27, 2149-2152.

(8) Tokiwa, Y.; Ugwu, C. U. Biotechnological Production of (R)-3Hydroxybutyric Acid Monomer. J. Biotechnol. 2007, 132, 264-272.

(9) Yeon, Y. J.; Park, H. Y.; Yoo, Y. J. Enzymatic Reduction of Levulinic Acid by Engineering the Substrate Specificity of 3Hydroxybutyrate Dehydrogenase. Bioresour. Technol. 2013, 134, 377-380.

(10) Fluchter, S.; Follonier, S.; Schiel-Bengelsdorf, B.; Bengelsdorf, F. R.; Zinn, M.; Durre, P. Anaerobic Production of Poly(3Hydroxybutyrate) and Its Precursor 3-Hydroxybutyrate from Synthesis Gas by Autotrophic Clostridia. Biomacromolecules 2019, 20, 3271-3282.

(11) Lee, H.-S.; Na, J. G.; Lee, J.; Yeon, Y. J. Structure-Based Mutational Studies of D-3-Hydroxybutyrate Dehydrogenase for Substrate Recognition of Aliphatic Hydroxy Acids with a Variable Length of Carbon Chain. Biotechnol. Bioprocess Eng. 2019, 24, 605612.

(12) Hoque, M. M.; Shimizu, S.; Hossain, M. T.; Yamamoto, T.; Imamura, S.; Suzuki, K.; Tsunoda, M.; Amano, H.; Sekiguchi, T.; Takenaka, A. The Structures of Alcaligenes Faecalis D-3-Hydroxybutyrate Dehydrogenase before and after $\mathrm{Nad}+$ and Acetate Binding Suggest a Dynamical Reaction Mechanism as a Member of the Sdr Family. Acta Crystallogr., Sect. D: Biol. Crystallogr. 2008, 64, 496-505.

(13) Kanazawa, H.; Hoque, M. M.; Tsunoda, M.; Suzuki, K.; Yamamoto, T.; Kawai, G.; Kondo, J.; Takenaka, A. Structural Insights into the Catalytic Reaction Trigger and Inhibition of D-3Hydroxybutyrate Dehydrogenase. Acta Crystallogr., Sect. F: Struct. Biol. Commun. 2016, 72, 507-515.

(14) Hoque, M. M.; Shimizu, S.; Juan, E. C.; Sato, Y.; Hossain, M. T.; Yamamoto, T.; Imamura, S.; Suzuki, K.; Amano, H.; Sekiguchi, T.; Tsunoda, M.; Takenaka, A. Structure of D-3-Hydroxybutyrate Dehydrogenase Prepared in the Presence of the Substrate D-3Hydroxybutyrate and Nad+. Acta Crystallogr., Sect. F: Struct. Biol. Cryst. Commun. 2009, 65, 331-335.
(15) Nakashima, K.; Ito, K.; Nakajima, Y.; Yamazawa, R.; Miyakawa, S.; Yoshimoto, T. Closed Complex of the D-3-Hydroxybutyrate Dehydrogenase Induced by an Enantiomeric Competitive Inhibitor. J. Biochem. 2009, 145, 467-479.

(16) Paithankar, K. S.; Feller, C.; Kuettner, E. B.; Keim, A.; Grunow, M.; Strater, N. Cosubstrate-Induced Dynamics of D-3-Hydroxybutyrate Dehydrogenase from. FEBS J. 2007, 274, 5767-5779.

(17) Preuveneers, M. J.; Peacock, D.; Crook, E. M.; Clark, J. B.; Brocklehurst, K. D-3-Hydroxybutyrate Dehydrogenase from Rhodopseudomonas Spheroides. Kinetic Mechanism from Steady-State Kinetics of the Reaction Catalysed by the Enzyme in Solution and Covalently Attached to Diethylaminoethylcellulose. Biochem. J. 1973, 133, 133-157.

(18) Kluger, R.; Nakaoka, K.; Tsui, W.-C. Substrate Analog Studies of the Specificity and Catalytic Mechanism of D-3-Hydroxybutyrate Dehydrogenase. J. Am. Chem. Soc. 1978, 100, 7388-7392.

(19) Ringborg, R. H.; Woodley, J. M. The Application of Reaction Engineering to Biocatalysis. React. Chem. Eng. 2016, 1, 10-22.

(20) Machado, T. F. G.; Gloster, T. M.; da Silva, R. G. Linear Eyring Plots Conceal a Change in the Rate-Limiting Step in an Enzyme Reaction. Biochemistry 2018, 57, 6757-6761.

(21) Czekster, C. M.; Vandemeulebroucke, A.; Blanchard, J. S. Kinetic and Chemical Mechanism of the Dihydrofolate Reductase from Mycobacterium Tuberculosis. Biochemistry 2011, 50, 367-375.

(22) Ottolina, G.; Riva, S.; Carrea, G.; Danieli, B.; Buckmann, A. F. Enzymatic Synthesis of $\left[4 \mathrm{R}^{2} \mathrm{H}\right] \mathrm{NAD}(\mathrm{P}) \mathrm{H}$ and $\left[4 \mathrm{~S}-{ }^{2} \mathrm{H}\right] \mathrm{NAD}(\mathrm{P}) \mathrm{H}$ and Determination of the Stereospecificity of 7 Alpha- and 12 Alpha Hydroxysteroid Dehydrogenase. Biochim. Biophys. Acta, Protein Struct. Mol. Enzymol. 1989, 998, 173-178.

(23) Salomaa, P.; Schaleger, L. L.; Long, F. A. Solvent Deuterium Isotope Effects on Acid-Base Equilibria. J. Am. Chem. Soc. 1964, 86, $1-7$.

(24) Winter, G.; McAuley, K. E. Automated Data Collection for Macromolecular Crystallography. Methods 2011, 55, 81-93.

(25) Kabsch, W. Xds. Acta Crystallogr., Sect. D: Biol. Crystallogr. 2010, 66, 125-132.

(26) Winter, G. Xia2: An Expert System for Macromolecular Crystallography Data Reduction. J. Appl. Crystallogr. 2010, 43, 186190.

(27) Winter, G.; Waterman, D. G.; Parkhurst, J. M.; Brewster, A. S.; Gildea, R. J.; Gerstel, M.; Fuentes-Montero, L.; Vollmar, M.; MichelsClark, T.; Young, I. D.; Sauter, N. K.; Evans, G. Dials: Implementation and Evaluation of a New Integration Package. Acta Crystallogr. D Struct. Biol. 2018, 74, 85-97.

(28) Evans, P. R.; Murshudov, G. N. How Good Are My Data and What Is the Resolution? Acta Crystallogr., Sect. D: Biol. Crystallogr. 2013, 69, 1204-1214.

(29) McCoy, A. J.; Grosse-Kunstleve, R. W.; Adams, P. D.; Winn, M. D.; Storoni, L. C.; Read, R. J. Phaser Crystallographic Software. J. Appl. Crystallogr. 2007, 40, 658-674.

(30) Cowtan, K. The Buccaneer Software for Automated Model Building. 1. Tracing Protein Chains. Acta Crystallogr., Sect. D: Biol. Crystallogr. 2006, 62, 1002-1011.

(31) Cowtan, K. Fitting Molecular Fragments into Electron Density. Acta Crystallogr., Sect. D: Biol. Crystallogr. 2008, 64, 83-89.

(32) Langer, G.; Cohen, S. X.; Lamzin, V. S.; Perrakis, A. Automated Macromolecular Model Building for X-Ray Crystallography Using Arp/Warp Version 7. Nat. Protoc. 2008, 3, 1171-1179.

(33) Emsley, P.; Cowtan, K. Coot: Model-Building Tools for Molecular Graphics. Acta Crystallogr., Sect. D: Biol. Crystallogr. 2004, $60,2126-2132$.

(34) Murshudov, G. N.; Vagin, A. A.; Dodson, E. J. Refinement of Macromolecular Structures by the Maximum-Likelihood Method. Acta Crystallogr., Sect. D: Biol. Crystallogr. 1997, 53, 240-255.

(35) Schüttelkopf, A. W.; van Aalten, D. M. Prodrg: A Tool for High-Throughput Crystallography of Protein-Ligand Complexes. Acta Crystallogr., Sect. D: Biol. Crystallogr. 2004, 60, 1355-1363.

(36) Williams, C. J.; Headd, J. J.; Moriarty, N. W.; Prisant, M. G.; Videau, L. L.; Deis, L. N.; Verma, V.; Keedy, D. A.; Hintze, B. J.; 
Chen, V. B.; Jain, S.; Lewis, S. M.; Arendall, W. B., 3rd; Snoeyink, J.; Adams, P. D.; Lovell, S. C.; Richardson, J. S.; Richardson, D. C. Molprobity: More and Better Reference Data for Improved All-Atom Structure Validation. Protein Sci. 2018, 27, 293-315.

(37) Liu, H.; Naismith, J. H. An Efficient One-Step Site-Directed Deletion, Insertion, Single and Multiple-Site Plasmid Mutagenesis Protocol. BMC Biotechnol. 2008, 8, 91.

(38) Redelings, B. D.; Suchard, M. A. Joint Bayesian Estimation of Alignment and Phylogeny. Syst. Biol. 2005, 54, 401-418.

(39) Kapli, P.; Yang, Z.; Telford, M. J. Phylogenetic Tree Building in the Genomic Age. Nat. Rev. Genet. 2020, 21, 428-444.

(40) Niesen, F. H.; Berglund, H.; Vedadi, M. The Use of Differential Scanning Fluorimetry to Detect Ligand Interactions That Promote Protein Stability. Nat. Protoc. 2007, 2, 2212-2221.

(41) Søndergaard, C. R.; Olsson, M. H. M.; Rostkowski, M.; Jensen, J. H. Improved Treatment of Ligands and Coupling Effects in Empirical Calculation and Rationalization of Pka Values. J. Chem. Theory Comput. 2011, 7, 2284-2295.

(42) Huang, J.; MacKerell, A. D., Jr. Charmm36 All-Atom Additive Protein Force Field: Validation Based on Comparison to Nmr Data. J. Comput. Chem. 2013, 34, 2135-2145.

(43) Jorgensen, W. L.; Chandrasekhar, J.; Madura, J. D.; Impey, R. W.; Klein, M. L. Comparison of Simple Potential Functions for Simulating Liquid Water. J. Chem. Phys. 1983, 79, 926-935.

(44) Vanommeslaeghe, K.; Raman, E. P.; MacKerell, A. D. Automation of the Charmm General Force Field (Cgenff) Ii: Assignment of Bonded Parameters and Partial Atomic Charges. J. Chem. Inf. Model. 2012, 52, 3155-3168.

(45) Pavelites, J. J.; Gao, J.; Bash, P. A.; Mackerell, A. D., Jr A Molecular Mechanics Force Field for $\mathrm{Nad}+\mathrm{Nadh}$, and the Pyrophosphate Groups of Nucleotides. J. Comput. Chem. 1997, 18, 221-239.

(46) Ribeiro, J. V.; Bernardi, R. C.; Rudack, T.; Stone, J. E.; Phillips, J. C.; Freddolino, P. L.; Schulten, K. Qwikmd - Integrative Molecular Dynamics Toolkit for Novices and Experts. Sci. Rep. 2016, 6, 26536.

(47) Kalé, L.; Skeel, R.; Bhandarkar, M.; Brunner, R.; Gursoy, A.; Krawetz, N.; Phillips, J.; Shinozaki, A.; Varadarajan, K.; Schulten, K. Namd2: Greater Scalability for Parallel Molecular Dynamics. J. Comput. Phys. 1999, 151, 283-312.

(48) Neese, F. Software Update: The Orca Program System, Version 4.0. WIREs Comput. Mol. Sci. 2018, 8, e1327.

(49) Bannwarth, C.; Ehlert, S.; Grimme, S. Gfn2-Xtb-an Accurate and Broadly Parametrized Self-Consistent Tight-Binding Quantum Chemical Method with Multipole Electrostatics and Density-Dependent Dispersion Contributions. J. Chem. Theory Comput. 2019, 15, $1652-1671$.

(50) Tao, J.; Perdew, J. P.; Staroverov, V. N.; Scuseria, G. E. Climbing the Density Functional Ladder: Nonempirical MetaGeneralized Gradient Approximation Designed for Molecules and Solids. Phys. Rev. Lett. 2003, 91, 146401.

(51) Zhao, Y.; González-García, N.; Truhlar, D. G. Benchmark Database of Barrier Heights for Heavy Atom Transfer, Nucleophilic Substitution, Association, and Unimolecular Reactions and Its Use to Test Theoretical Methods. J. Phys. Chem. A 2005, 109, 2012-2018.

(52) Grimme, S.; Antony, J.; Ehrlich, S.; Krieg, H. A Consistent and Accurate $\mathrm{Ab}$ Initio Parametrization of Density Functional Dispersion Correction (Dft-D) for the 94 Elements H-Pu. J. Chem. Phys. 2010, 132, 154104.

(53) Kruse, H.; Grimme, S. A Geometrical Correction for the Interand Intra-Molecular Basis Set Superposition Error in Hartree-Fock and Density Functional Theory Calculations for Large Systems. J. Chem. Phys. 2012, 136, 154101.

(54) Zhao, Y.; Truhlar, D. G. The M06 Suite of Density Functionals for Main Group Thermochemistry, Thermochemical Kinetics, Noncovalent Interactions, Excited States, and Transition Elements: Two New Functionals and Systematic Testing of Four M06-Class Functionals and 12 Other Functionals. Theor. Chem. Acc. 2008, 120, 215-241.
(55) Zheng, J.; Xu, X.; Truhlar, D. G. Minimally Augmented Karlsruhe Basis Sets. Theor. Chem. Acc. 2011, 128, 295-305.

(56) Neese, F.; Wennmohs, F.; Hansen, A.; Becker, U. Efficient, Approximate and Parallel Hartree-Fock and Hybrid Dft Calculations. A 'Chain-of-Spheres' Algorithm for the Hartree-Fock Exchange. Chem. Phys. 2009, 356, 98-109.

(57) Li, H.; Jensen, J. H. Partial Hessian Vibrational Analysis: The Localization of the Molecular Vibrational Energy and Entropy. Theor. Chem. Acc. 2002, 107, 211-219.

(58) Cook, P. F.; Cleland, W. W. Mechanistic Deductions from Isotope Effects in Multireactant Enzyme Mechanisms. Biochemistry 1981, 20, 1790-1796.

(59) Johnson, K. A. In The Enzymes; Sigman, D. S., Ed.; Academic Press, 1992; Vol. 20, pp 1-61.

(60) Patel, M. P.; Liu, W. S.; West, J.; Tew, D.; Meek, T. D.; Thrall, S. H. Kinetic and Chemical Mechanisms of the Fabg-Encoded Streptococcus Pneumoniae Beta-Ketoacyl-Acp Reductase. Biochemistry 2005, 44, 16753-16765.

(61) Cleland, W. W. Determining the Chemical Mechanisms of Enzyme-Catalyzed Reactions by Kinetic Studies. Adv. Enzymol. Relat. Areas Mol. Biol. 2006, 45, 273-387.

(62) Schowen, K. B.; Schowen, R. L. Solvent Isotope Effects of Enzyme Systems. Methods Enzymol. 1982, 87, 551-606.

(63) Fernandez, P. L.; Murkin, A. S. Inverse Solvent Isotope Effects in Enzyme-Catalyzed Reactions. Molecules 2020, 25, 1933.

(64) Hermes, J. D.; Roeske, C. A.; O'Leary, M. H.; Cleland, W. W. Use of Multiple Isotope Effects to Determine Enzyme Mechanisms and Intrinsic Isotope Effects. Malic Enzyme and Glucose-6-Phosphate Dehydrogenase. Biochemistry 1982, 21, 5106-5114.

(65) Silva, R. G.; de Carvalho, L. P.; Blanchard, J. S.; Santos, D. S.; Basso, L. A. Mycobacterium Tuberculosis Beta-Ketoacyl-Acyl Carrier Protein (Acp) Reductase: Kinetic and Chemical Mechanisms. Biochemistry 2006, 45, 13064-13073.

(66) Krissinel, E.; Henrick, K. Inference of Macromolecular Assemblies from Crystalline State. J. Mol. Biol. 2007, 372, 774-797.

(67) Ito, K.; Nakajima, Y.; Ichihara, E.; Ogawa, K.; Katayama, N.; Nakashima, K.; Yoshimoto, T. D-3-Hydroxybutyrate Dehydrogenase from Pseudomonas Fragi: Molecular Cloning of the Enzyme Gene and Crystal Structure of the Enzyme. J. Mol. Biol. 2006, 355, 722733.

(68) Mlýnský, V.; Banáš, P.; Šponer, J.; van der Kamp, M. W.; Mulholland, A. J.; Otyepka, M. Comparison of Ab Initio, Dft, and Semiempirical QM/MM Approaches for Description of Catalytic Mechanism of Hairpin Ribozyme. J. Chem. Theory Comput. 2014, 10, $1608-1622$.

(69) Goerigk, L.; Hansen, A.; Bauer, C.; Ehrlich, S.; Najibi, A.; Grimme, S. A Look at the Density Functional Theory Zoo with the Advanced Gmtkn55 Database for General Main Group Thermochemistry, Kinetics and Noncovalent Interactions. Phys. Chem. Chem. Phys. 2017, 19, 32184-32215.

(70) Cooper, A. M.; Kästner, J. Averaging Techniques for Reaction Barriers in QM/MM Simulations. ChemPhysChem 2014, 15, 32643269.

(71) Feller, C.; Günther, R.; Hofmann, H. J.; Grunow, M. Molecular Basis of Substrate Recognition in D-3-Hydroxybutyrate Dehydrogenase from Pseudomonas Putida. ChemBioChem 2006, 7, 1410-1418. 